\title{
ESTAMPILLAS ANFÓRICAS Y GRAFITOS PÚNICOS RECUPERADOS EN EL SOLAR DE "LOS CHINCHORROS” (CALLE SAN BARTOLOMÉ, CÁDIZ)
}

\author{
PUNIC AMPHORA STAMPS AND GRAFFITI FOUND IN THE AREA OF \\ “LOS CHINCHORROS” (SAN BARTOLOMÉ STREET, CÁDIZ)
}

\section{José Ángel ZAMORA LÓPEZ ${ }^{1 *}$, Antonio M. SÁEZ ROMERO** y María Luisa LAVADO FLORIDO***}

${ }^{1}$ Consejo Superior de Investigaciones Científicas, Instituto de Lenguas y Culturas del Mediterráneo y Oriente Próximo, Centro de Ciencias Humanas y Sociales, Calle Albasanz 26-28, 28037, Madrid

${ }^{2}$ Universidad de Sevilla, Departamento de Prehistoria y Arqueología, Facultad de Geografía e Historia, Calle Doña María de Padilla s/n, 41004, Sevilla

${ }^{3}$ Arqueóloga

* Correo electrónico: joseangel.zamora@csic.es

** Correo electrónico: asaez1@us.es

***Correo electrónico: marialuisa_lavado@hotmail.com

Resumen: Durante los años 2007 y 2008 fueron llevadas a cabo excavaciones arqueológicas preventivas, bajo la dirección de M. L. Lavado, en la zona conocida popularmente como "Los Chinchorros", a extramuros de la ciudad moderna de Cádiz. Los trabajos permitieron recuperar datos sobre la distribución al sur del recinto urbano de Gadir/Gades de la necrópolis fenicia arcaica, de los saladeros de pescado púnicos y de otras actividades artesanales y funerarias de época romana republicana e imperial. Los contextos excavados en relación a la actividad conservera de época púnica y tardopúnica aportaron una ingente cantidad de material mueble, entre el cual destaca el enorme número de ánforas y fragmentos de vajilla barnizada documentados en algunas fosas empleadas como vertedero. Entre estos materiales sobresale la presencia de varios sellos anfóricos, tanto locales como de origen púnico centromediterráneo, así como varios grafitos grabados sobre piezas de vajilla. El escaso número de marcas de estos tipos estudiadas en el ámbito de la bahía, así como el contenido epigráfico e iconográfico de los sellos y su relación con contextos artesanales han motivado su estudio específico, aportando nuevos indicadores sobre fenómenos de compleja lectura histórica como el relativo al sellado de las ánforas. Se presentan cinco marcas inéditas correspondientes a la actividad de talleres locales y tres más (epígrafes bilíteros en dos de los casos) asociadas a importaciones de envases de transporte cartagineses.

Palabras Clave: Fenicios, Gadir, epigrafía, comercio, salazones, Cartago.

\begin{abstract}
The salvage excavations carried out during 2007 and 2008 conducted and directed by M. L. Lavado in the area popularly known as "Los Chinchorros", outside the walls of the modern city of Cadiz, allowed the recovery of archaeological data from the south of the urban area of Gadir/Gades. This new data attested the presence there of the archaic Phoenician necropolis, Punic fish salting facilities and other artisanal and funerary areas dating to the Roman period. The contexts excavated in relation to the Punic and late Punic fish processing activities provided an outstanding amount of artifacts, including a large number of amphorae and fragments of glazed tableware documented in some dumping pits. Among these materials, the presence of several amphorae stamps, both local and of Carthaginian origin, stands out, as well as several graffiti engraved on tableware vessels. The limited number of marks of these types that have been studied in the area of Cadiz bay, as well as the epigraphic and iconographic content of the stamps and their relationship with artisanal contexts have motivated a specific analysis, providing new insights about phenomena of complex historical interpretation such as the stamping of amphoras. Eight unpublished marks are discussed, five corresponding to the activity of local pottery workshops, and three more (biliteral epigraphs in two of the cases) that can be linked to Carthaginian transport containers.
\end{abstract}

Keywords: Phoenicians, Gadir, epigraphy, trade, salted fish, Carthage. 
Sumario: 1. Introducción: objetivos y metodología. 2. Las excavaciones en Los Chinchorros (2007-2008). Síntesis de los resultados. 3. Las marcas, los soportes y sus contextos. 3.1. El vertedero Fosa 5 (cuadros C1/D1). 3.2. Los niveles de amortización del horno y su entorno (cuadro D5). 3.3. El pozo PZ-5 (cuadro C14). 4. Estudio epigráfico de los hallazgos. 4.1. Estampillas sobre ánforas cartaginesas (fosa de los cuadros C1/D1, Nivel 2). 4.2. Grafito postcocción en la base de cuenco "de tipo Kuass" (fosa de los cuadros C1/D1, Nivel 2). 4.3. Grafito postcocción en la base de pátera de barniz negro (cuadro D5). 4.4. Grafito postcocción sobre bol de barniz negro itálico (cuadro D5). 4.5. Estampilla circular sobre ánfora gaditana (cuadro C14, pozo PZ-5). 5. Conclusiones. 6. Agradecimientos. 7. Bibliografía.

\section{Introducción: objetivos y metodología}

En los últimos años la zona conocida como "extramuros" de Cádiz, es decir, la parte norte de la antigua isla de Kotinoussa, ha mostrado que además de un intenso uso como área funeraria se desarrollaron en ella otras muchas actividades relacionadas con la vida del asentamiento fenicio, púnico y romano de Gadir/Gades. Numerosas excavaciones de tipo preventivo han ido revelando pequeñas partes del puzzle que constituye este sector de la zona insular de la bahía, aportando pinceladas de la existencia de implantaciones de carácter artesanal que se intercalaron entre el viario, parcelas agrícolas y grandes extensiones ocupadas con diferente intensidad (dependiendo del momento) por tumbas y mausoleos. Por tanto, la imagen que vamos dibujando en los últimos años sobre esta zona es mucho más rica y variada de lo asumido; en el área se aprecian usos del suelo muy dinámicos, que se fueron adaptando a los cambios operados en la planificación urbanística del recinto urbano y a las necesidades de los sectores artesanales locales entre la etapa fenicia arcaica avanzada y la fase romana bajoimperial.

El conocido popularmente como "solar de Los Chinchorros", cuyo estudio da pie a estas páginas, es una de las piezas clave de este puzzle al que antes aludíamos. Su estudio en el marco de la tesis doctoral de uno de los autores (Antonio M. Sáez Romero) ha revelado una interesante secuencia de utilización que incluyó varios grupos de cremaciones fenicias, un saladero de pescado y pozos de época púnica y tardopúnica (siglos V-II a.C.), numerosos enterramientos, pozos y piletas de época romana tardorrepublicana e imperial, e incluso trazas de cantería de esta misma fase, además de un tramo bien conservado de la vía o "camino del arrecife" de época medieval - moderna (una primera síntesis en Sáez y Lavado, 2019). En las dos últimas décadas también ha cambiado y se ha incrementado el conocimiento existente sobre el material mueble asociado a estas áreas, con un particular énfasis sobre aquellos ítems vinculados a contextos de uso funerario o ceremonial (Niveau de Villedary, 2003, 2009). El consumo de alimentos envasados en ánforas, así como la utilización de determinados elementos de vajilla en estos escenarios externos a la ciudad de Gadir/Gades, han sido uno de los frentes de avance más destacados. Hasta ahora se había sin embargo atendido, no tanto a una visión de contexto, sino más bien a la publicación de síntesis o de piezas de algún modo "excepcionales" (entre ellas, ánforas cartaginesas estampilladas encontradas en fosas y pozos; cf. Niveau de Villedary y Zamora, 2009; Zamora y Niveau de Villedary, 2008; Zamora, 2010). Estos avances en el área tradicionalmente asignada a la necrópolis insular se enmarcan asimismo en un momento de notable incremento en los datos paleogeográficos; de aumento del conocimiento sobre la evolución urbana y periurbana en la isla Erytheia y en el extremo septentrional de la propia Kotinoussa; de adquisición de nuevas informaciones provenientes de la orilla continental de la bahía; y de considerable progreso en la investigación de los centros rurales y alfareros situados en la actual San Fernando.

El panorama actual es por consiguiente mucho más complejo y rico en matices, tanto desde el punto de vista urbanístico o de los patrones de gestión del territorio como en relación al estudio de los ritmos de producción, circulación y consumo de bienes. En este marco situamos esta contribución, que pretende dar a conocer elementos singulares documentados en el área "extramuros" de Cádiz, pero en este caso sin desligarlos de sus datos contextuales y aportando por tanto una interpretación conjunta que ayude, por un lado, a arrojar luz sobre la dinámica de uso del solar de Los Chinchorros; pero también, por otro, a comprender las tendencias de recepción y consumo de 
determinados productos en los ambientes artesanales insertos entre las áreas funerarias del norte insular de la bahía. En este caso, los documentos estudiados en estas páginas (estampillas epigráficas y anepígrafas locales o importadas, grafitos incisos sobre elementos de vajilla, etc.) permiten ilustrar algunos de los contextos más significativos de la secuencia de uso y abandono del saladero de pescado, de época púnica, localizado en el solar, sobre los cuales presentaremos también un avance de su estudio. Se trata por tanto de un estudio arqueológico y epigráfico de marcas diversas, sobre distintos tipos de soportes, que no sólo pretende discutir dichos ítems sino también contextualizarlos y dar a conocer nuevas informaciones sobre las fases del yacimiento en las cuales se insertan. Ello dará pie a reflexionar brevemente sobre la evolución de los usos del suelo en esta zona volcada hacia el Atlántico, y también a analizar de forma sintética el consumo de productos locales y foráneos en este tipo de instalaciones artesanales del territorio de Gadir/Gades.

\section{Las excavaciones en Los Chinchorros (2007- 2008). Síntesis de los resultados}

Las excavaciones preventivas desarrolladas en 2007-2008 (dirigidas por M. L. Lavado Florido) permitieron investigar una interesante secuencia que se extiende entre la Prehistoria Reciente y la época moderna, englobando en los diversos estratos usos sucesivos que tienen que ver con la necrópolis fenicia y romana, parte de un complejo de producción de salazones cuya actividad debió extenderse en diversas fases desde al menos inicios del siglo $\mathrm{V}$ a.C. hasta el tramo final del siglo II a.C. o inicios del siglo I a.C., actividades extractivas de época romana (cantera) y parte del llamado "camino del arrecife" que unió por tierra las localidades de Cádiz y San Fernando desde época bajomedieval hasta el maremoto de 1755. El área objeto de estudio (Figura 1) había tenido como último uso el residencial, con pequeñas viviendas particulares adosadas de una sola planta no dotadas de sótano ni garaje, las cuales fueron demolidas previamente al planteamiento de un proyecto de construcción de nueva planta, y que está aún en proceso de ejecución. El solar cuenta con accesos por dos vías que lo delimitan al oeste (calle San Juan Bautista) y al norte (calle San Bartolomé), estando el resto de laterales o medianeras ocupadas por edificaciones preexistentes u otras vías secundarias (al sur, la calle Marqués de Coprani; al este-noreste las casas colindantes con la Avenida Ana de Viya y la plaza Jesús de la Paz).

El espacio proyectado para la construcción de los edificios de nueva planta de VPO dotados de garaje que motivaban la intervención contaba con un perímetro irregular, ocupando una superficie de 4.688,93 $\mathrm{m}^{2}$, de los cuales serían finalmente edificados la práctica totalidad. En este nuevo proyecto se tenía prevista la creación de dos plantas de sótano-garaje que alcanzarían una cota inferior a los 6 metros de profundidad desde la rasante de la calle, afectando por tanto su construcción a los niveles arqueológicos que las actuaciones precedentes en el entorno habían evidenciado. Las actuaciones anteriores llevadas a cabo en el entorno (especialmente el solar de la calle Arcángel San Miguel c/v Plaza del Santo Ángel de la Guarda, así como el del parking subterráneo construido en la Plaza Jesús de la Paz) proporcionaron un número elevadísimo de enterramientos, confirmando la extensión de la necrópolis gaditana hacia el sur en época imperial; también pudo verificarse que se trataba no de un área de media densidad si no de "alta densidad" (Arévalo y Moreno, 2016). Sobre la base de estos indicadores fue descartada la necesidad de realizar sondeos previos, planteándose directamente la excavación extensiva en la totalidad del suelo a edificar.

La intervención fue autorizada por la Dirección General de Bienes Culturales de la Junta de Andalucía con fecha de 19 de septiembre de 2007, dando comienzo el día 5 de noviembre y finalizando las tareas de excavación de campo y procesado de los materiales el día 23 de marzo de 2008. Tras concluir esta primera fase, los trabajos arqueológicos habían liberado de cautelas casi la totalidad de la parcela, pero una parte de la misma no se había intervenido por permanecer aún en pie una antigua nave industrial (zona noreste-oriental del solar). Consecuentemente, fue necesario proyectar una segunda fase de actuaciones, que se desarrolló finalmente entre los meses de abril y agosto de 2008 (Lavado, 2008). Se planteó una excavación extensiva desde el inicio ( $\sin$ catas previas o testigos estratigráficos), ante la previsible aparición de gran cantidad de estructuras funerarias aisladas y dispersas, como en los solares excavados precedentemente en el entorno. Esta segunda fase se concentró en la excavación del sector noreste del solar, donde se situaban los restos de instalaciones conserveras de época púnica-tardopúnica, algu- 


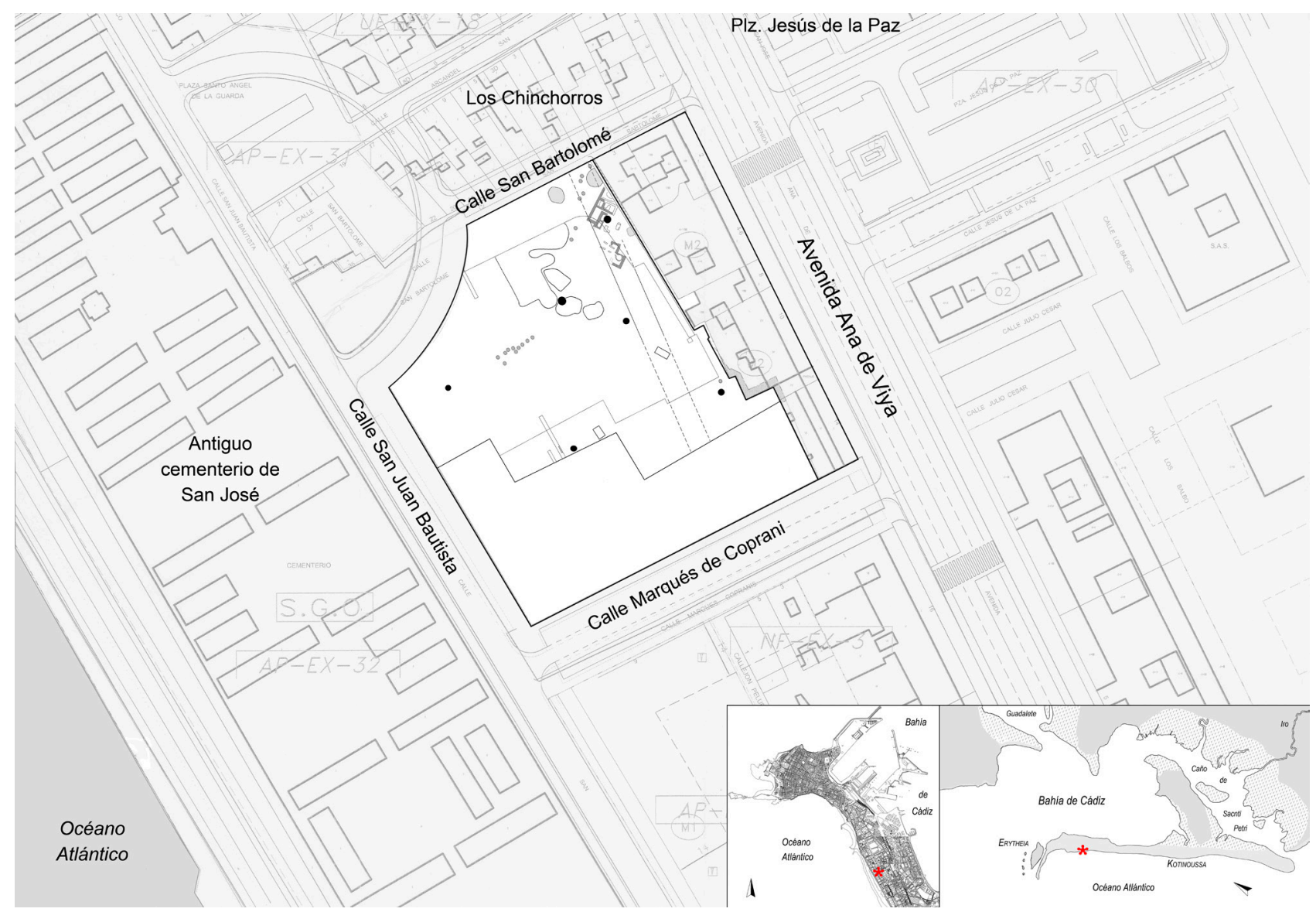

Figura 1. Plano del área de la ciudad de Cádiz donde se sitúa el solar de Los Chinchorros, mostrando los principales hallazgos registrados en la parcela en las actuaciones de 2007-2008. En recuadro, el asterisco señala la ubicación del solar en el plano actual de Cádiz (izq.) y sobre propuesta de reconstrucción de la paleotopografía insular (dcha.).

nos vertederos asociados y restos muy arrasados de enterramientos arcaicos de cremación.

La primera etapa de la intervención abarcó unos dos tercios de la parcela, quedando en reserva para la segunda fase una franja irregular de unos 10 metros de ancho en los laterales norte, este y sur (en estas zonas sólo se retiraron las capas superficiales de escombros y duna estéril en esta primera fase). Del mismo modo, en la etapa inicial de los trabajos los hallazgos se vincularon fundamentalmente a enterramientos (tanto cremaciones fenicias como enterramientos romanos), estructuras subsidiarias de estos usos funerarios (pozos, piletas), algunos muros dispersos (M1, M2), restos del viario de época moderna y una gran área de cantera de época romana imperial (Fosas 1 a 4, situadas entre los cuadros F3/G3/H3/I3). Por el contrario, en la segunda fase se documentaron más tumbas (esencialmente cremaciones fenicias, C-12 a C-19) y estructuras de época romana vinculadas a los enterramientos romanos de la fase uno de la actua- ción (pileta PL-2, pozos PZ-4/PZ-5, canalización), pero sobre todo la intervención se concentró en la documentación de las estructuras y vertederos del complejo conservero situados en el sector delimitado por las cuadrículas C/D/E 1-5 (Figura 2).

En la Fase 1 de la actuación las estructuras funerarias registradas en todo el perímetro del solar se restringieron a once cremaciones y una inhumación, las cremaciones aparentemente vinculadas a una ocupación fenicia arcaica y la inhumación a la necrópolis gaditana altoimperial (Sáez y Lavado, 2019: 57, fig. 2). Las cremaciones documentadas en esta primera etapa ( $\mathrm{C}-1$ a $\mathrm{C}-11$ ) repiten en general la misma tipología, fosas excavadas en los niveles arcillosos sin canal central ni cubiertas elaboradas, y conformando una concentración ordenada casi lineal entre los cuadros I7/J7/K7 (tumbas C-1 a C-10). Por su parte, la "Inhumación 1" se documentó a una cota superior de las cremaciones (en concreto, se encontraba por encima de la C-8), correspondiendo a una fosa practicada en un ni- 


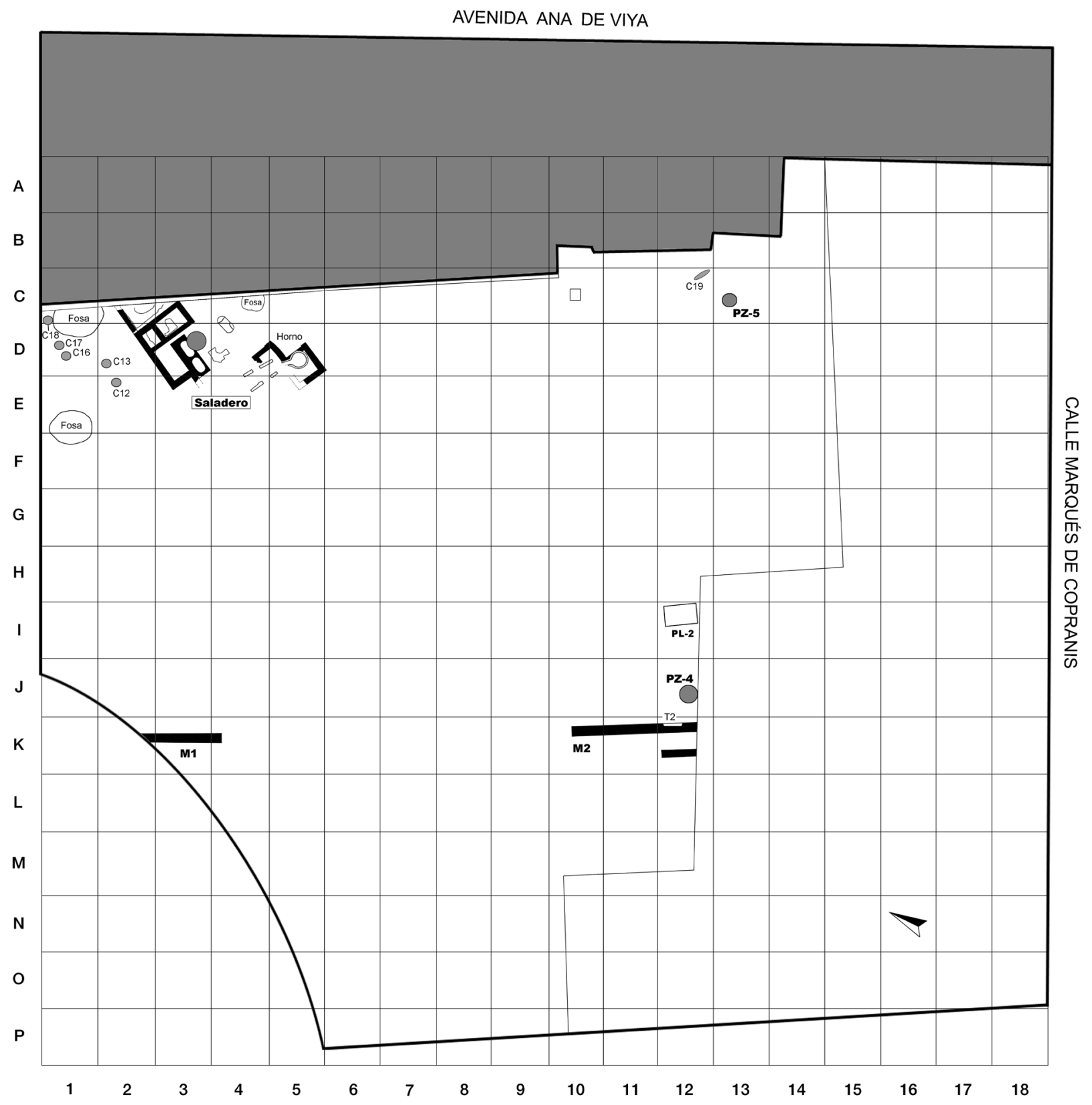

Figura 2. Planta general de las estructuras documentadas en la Fase 2 de la actividad arqueológica, mostrando la ubicación de las cremaciones fenicias, de los pozos y piletas, así como de las estructuras (muros y vertederos) asociados a la actividad conservera púnica y tardopúnica.

vel de arenas pardas rematada con una cubierta de tégulas dispuestas a dos aguas, sin ajuar, aunque asociada a dos ases de época de Trajano. En la zona norte del solar pudieron documentarse bajo el trazado de la calzada medieval-moderna evidencias de una estructura hidráulica construida entre los cuadros D4/D5, un estanque o pileta (PL-1) de época tardorrepublicana muy arrasada que habría contado con escalones laterales en al menos uno de sus lados. Varios puntos de captación de aguas se ubicaban también en este sector, como los pozos PZ-1 (cuadro N7), PZ-2 (cuadro G6) y PZ-3 (cuadro E8), de los cuales sólo el segundo proporcionó en su relleno material diagnóstico que sugiere una colmatación entre los siglos I-II d.C. Otros restos de muros y una pequeña fosa con materiales de finales del siglo III a.C. se documentaron en la zona sur-suroeste del solar (cuadros K3/K4 y K10/12), aunque no pudo clarificarse su conexión con el edificio conservero o con otras estructuras. 
En la Fase 2 de los trabajos arqueológicos (Figura 2) pudieron documentarse también vestigios de los mismos tipos de estructuras funerarias localizadas en la primera fase (Sáez y Lavado, 2019: 58, fig. 3), destacando el numeroso grupo de cremaciones fenicias del cuadrante norte y algunas sepulturas de época romana aisladas, asociadas en el caso del cuadro $\mathrm{C} 10$ a una pileta documentada en la fase anterior (PL-1) y en el del cuadro K12 a una nueva estructura similar (PL-2) y a un pozo (PZ4). La "Inhumación 2" (cuadro K12) corresponde a un enterramiento en fosa en buen estado de conservación, en este caso portando como ajuar en la mano derecha una jarrita de cerámica común y una moneda (as de bronce de Trajano) colocada sobre la cadera. Este enterramiento presenta características y una posición estratigráfica que apuntan a su coetaneidad con la "Inhumación 1", con la PL-2 y con el PZ-4, todos ellos fechados en la fase altoimperial. Por su parte, las cremaciones fenicias ( $\mathrm{C}-12$ a C-18, situadas entre los cuadros D1/D2 y E2) presentaban en general el mismo formato estructural; se trataba en todos los casos de cremaciones primarias, realizadas dentro de fosas dobles cavadas en las "arcillas rojas", sin cubierta y sin elementos de ajuar asociados. Finalmente, la ampliación del área de excavación en el sector oriental del solar permitió verificar la presencia de otra cremación primaria en fosa de época fenicia arcaica (C-19, situada en el cuadro C14) ubicada en la roca base que proporcionó un rico y variado ajuar dotado con piezas de marfil decoradas, objetos de joyería, etc. (Lavado, 2010). Muy próximo a este enterramiento, aunque a una cota superior, se localizaron los restos de otro pozo (PZ-5) amortizado en época tardopúnica, labrado en los estratos geológicos y junto a cuyo brocal se localizaron varias ánforas prácticamente completas que parece fechan el momento final de actividad.

Además de estos testimonios funerarios fenicios y romanos, en el ángulo norte del solar pudo documentarse la continuidad de la calzada medieval-moderna en dirección norte, adentrándose bajo la calle San Bartolomé y las casas anexas. Aproximadamente bajo el trazado de este viario, en una amplia franja de unos $12 \times 26 \mathrm{~m}$ pudieron localizarse finalmente estructuras correspondientes a un saladero de pescado púnico (ambientes A-G) y a vertederos documentados anexos al núcleo productivo (Fosas 5, 6 y 7), algunos de los cuales afectaron a las cremaciones fenicias localizadas en los cuadros D1/D2 y E2, antes citadas. Los hallazgos de las ex- cavaciones de 2007-2008 en general y las estructuras de carácter artesanal documentadas sólo han sido objeto por ahora de publicación preliminar (Sáez, 2014: 166; Sáez y Lavado, 2016, 2019), por lo que este trabajo constituye un nuevo avance en la presentación científica de los resultados de estos trabajos preventivos en Los Chinchorros.

Las estructuras que hemos interpretado como pertenecientes al complejo conservero estaban caracterizadas por la presencia de un edificio de tendencia rectangular con varias estancias (algunas dotadas con suelos de cocciopesto [opus signinum] correspondientes a la última fase de uso del edificio) y un mínimo de tres piletas ovaladas (Sáez y Lavado, 2019: 66-72, fig. 3). Los vertederos de mayores dimensiones se ubicaron en el siglo $\mathrm{V}$ entre los cuadros E1/F1 mientras que entre los siglos IV-III a.C. estuvieron ubicados al norte del complejo edilicio dando lugar a una gran fosa en el área entre los cuadros C1/D1 (la cual tuvo dos grandes fases sucesivas de vertido de ingentes cantidades de ánforas y otros desechos generados por el saladero). En el cuadro D5 se excavó también un horno de pequeñas dimensiones cuya tipología en planta coincide con los patrones generales de las piroestructuras alfareras locales (cámara circular, corredor), aunque en este caso carecía de pilar o columna central y no se recuperaron desechos o huellas de combustión que permitiesen atribuirle con seguridad dicha funcionalidad, perteneciendo en cualquier caso a una etapa tardía del uso artesanal del sector.

A modo de síntesis, puede decirse que la secuencia de ocupación antrópica de este sector "extramuros" de Cádiz tuvo un primer episodio con alguna actividad o pequeño asentamiento en la Prehistoria Reciente que debió conllevar al menos un enterramiento de inhumación, tal y como sugieren algunas cerámicas y restos óseos revueltos documentados en la fosa de los cuadros E/F1. Ya en el I milenio a.C., la zona parece haber estado ocupada en origen por diversas áreas de enterramiento de cremación de época fenicia arcaica avanzada (constituyendo al menos dos grupos) y por un enterramiento aislado, correspondiendo a las tipologías habituales en la necrópolis insular. El uso y quizá la ordenación espacial de estos espacios debió modificarse a raíz de los cambios sustanciales acaecidos a la ciudad en la segunda mitad del siglo VI a.C., puesto que estos enterramientos fueron parcialmente dañados por la construcción posterior de un primer edificio conserve- 
ro cuya estructura inicial y número de balsas no se ha podido determinar. No obstante, los vertederos distribuidos en torno a este núcleo indican una importante actividad entre los siglos V-III a.C., siendo abundantísimos los envases anfóricos locales e importados documentados en estos testares, así como restos de vajillas presumiblemente usadas por los trabajadores del complejo.

Lamentablemente, no es posible caracterizar la evolución del edificio en esta fase púnica, aunque es probable que pudiera haberse dado una transición parecida a la detectada en el caso del yacimiento Puerto 19 (Sáez et al., 2020a), puesto que los vertidos correspondientes a los siglos IV-III a.C. se concentran en áreas diferentes a los del siglo $\mathrm{V}$ a.C. En el siglo II a.C., quizá en su primera mitad o a mediados de la centuria, el complejo parece sufrir una profunda reforma y ampliación, englobando hasta cuatro piletas ovales (tres de ellas conservadas in situ), varias estancias pavimentadas con cocciopesto y un horno de planta circular con un pequeño corredor (cuya virtual funcionalidad alfarera no ha podido constatarse con total rotundidad). Algunos pozos, como el localizado en la cuadrícula C14 (PZ-5), habrían estado ya activos en la fase anterior y parecen amortizarse también entre finales del siglo II a.C. y en los inicios del I a.C., momento en el cual el saladero parece que cesó definitivamente su actividad. A partir de ese momento, la zona parece quedar sin aparente uso (acaso agrícola), proliferando la instalación dispersa de piletas escalonadas, algún pozo y enterramientos aislados quizá vinculados a dichas estructuras, dentro de una dinámica de progresivo uso funerario exclusivo que acabaría, ya en época romana imperial, con la instalación en la zona central de la parcela de una cantera, probablemente destinada a la extracción de áridos.

\section{Las marcas, los soportes y sus contextos}

Tal y como señalamos en la introducción de este trabajo, centraremos la atención en un reducido número de hallazgos registrados en varios contextos de las excavaciones realizadas en el solar de Los Chinchorros. En concreto, fijaremos la mirada sobre algunas piezas que portan marcas selladas o incisas, en algunos casos grafemáticas, y también sobre sus contextos de hallazgo, tratando de aportar a través de su análisis algunas claves para la interpretación de la secuencia del solar y en particular del saladero de pescado púnico localizado en su sector noreste. Estos ítems pueden clasificarse en al menos tres tipos de marcas distintas (sellos sin grafemas, sellos con grafemas y grafitos incisos post-cocción) que, como veremos, se relacionan con soportes de origen, cronología y tipología diversos. Por ello, presentaremos las piezas agrupadas por sus contextos de hallazgo (Figura 3), lo que permitirá tener una imagen general, en orden diacrónico, de los documentos analizados. En cualquier caso, se trata de ítems vinculados a las diversas fases de uso del edificio conservero o de construcciones asociadas a su actividad, algo que ha quedado reflejado en su distribución, limitada únicamente a la franja este del solar.

\subsection{El vertedero Fosa 5 (cuadros C1/D1)}

Se trata de una fosa profunda abierta en los niveles arcillosos de la base geológica, cuyo proceso de labra muy probablemente dañó o eliminó parte de la agrupación de cremaciones arcaicas situada en las inmediaciones (C-5 y C-11 a C-18). Aglutinó todo tipo de desechos generados en el saladero a juzgar por el ingente volumen de elementos cerámicos recuperados. Se ha observado una posible coetaneidad o continuidad entre este vertedero y la Fosa 7, si bien el evidente esfuerzo planificador a largo plazo ejemplificado por la Fosa 5 no puede asociarse con cambios concretos en el diseño del saladero, pues se carece de evidencias directas sobre posibles reformas en la distribución o incluso sobre el número de piletas activas en esta fase. En cualquier caso, el examen de los testimonios muebles sugiere que debió tratarse de una etapa de notable impulso productivo y de continuidad de la actividad artesanal, que sobre todo se sitúa entre mediados del siglo IV y los dos primeros tercios del III a.C., siendo por tanto depósitos muy similares a los detectados en la Fase 2 del asentamiento rural portuense de Puerto 19 (Sáez et al., 2020a).

El relleno de la Fosa 5 presentó dos facies arqueológicas diferenciadas, con leves matices de composición del sedimento marrón/grisáceo, si bien en realidad se trata sólo de dos caras de una misma moneda, ya que la formación del depósito no debió necesitar sólo de dos esfuerzos sino de una deposición continuada durante varias décadas. Esta distinción estratigráfica, que no se refleja desde una perspectiva tipológica en la existencia de agrupaciones claramente diferenciadas (como demuestran los materiales que a continuación analizamos), determina que presentemos en pri- 


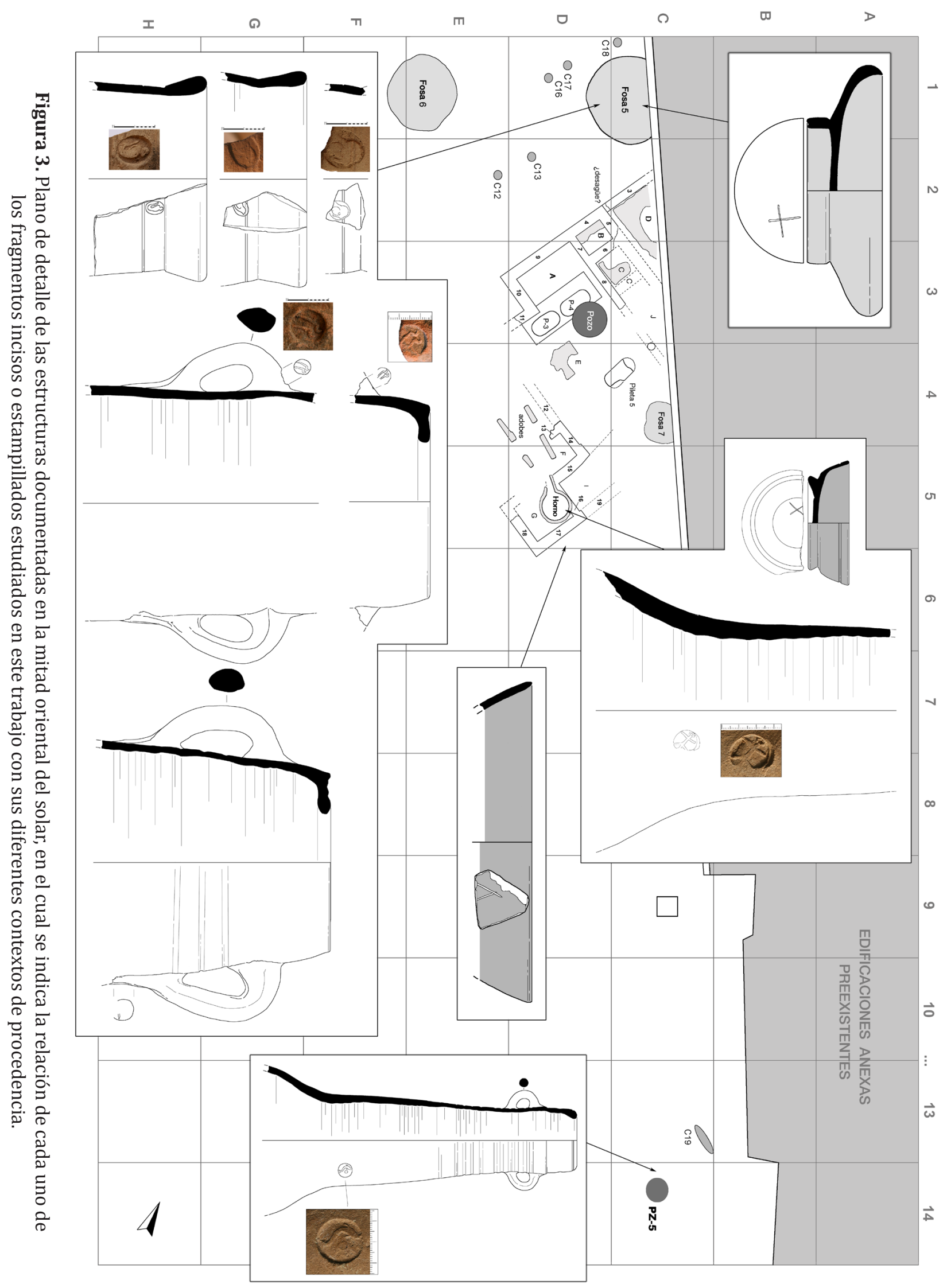

Revista Atlántica-Mediterránea de Prehistoria y Arqueología Social 22, pp. 139-168 Universidad de Cádiz 
mer lugar el análisis de los objetos del nivel más profundo (2) para terminar examinando el ítem recuperado en el más superficial y reciente (1), con el objetivo de emplear un criterio crono-estratigráfico en nuestro estudio.

El nivel 2 de la Fosa 5 se dispuso en la zona exterior del saladero (al norte del edificio), colocando las primeras descargas directamente sobre la base irregular labrada en las arcillas de la base geológica, sin que se haya observado ni una especialización de los vertidos (por tipos o familias predominantes) ni una distribución intencional por áreas dentro de la gran fosa. En este estrato profundo de la fosa las ánforas gadiritas constituyen el grupo más ampliamente representado, mostrando una diversidad tipológica muy similar a la observada en la Fosa 7 pero en una cantidad masiva (están presentes residualmente algunas T-11210, pero sobre todo individuos de los tipos T-12111 y T-12111/2, y especialmente T-8211).

Entre esta gran masa de ánforas T-8211 locales destaca la aparición de dos individuos sellados: se trata de dos estampillas con cartelas de tendencia oval y pequeño tamaño (menos de $2 \mathrm{~cm}$ de longitud y poco más de 1 de anchura) dispuestas bajo el borde, justo a la altura de la inflexión hacia el cuerpo y en relación a la típica incisión que marca la altura de la unión superior de las asas. Frente a esta coincidencia de perfil y posición, las representaciones que presentan las estampillas son como veremos diversas, así como el diseño de la composición. Las dos marcas resultan muy informativas en relación al proceso de producción de las ánforas locales y al momento de colocación sobre los envases de estos sellos. En los dos, la observación con lupa de las superficies permite determinar que se trata de matrices planas regulares, sin gráfilas u otros ornamentos como enmarque de los motivos centrales; y en ambos casos fueron aplicadas sobre la superficie de la arcilla cuando esta conservaba aún un grado elevado de humedad, lo que explica por qué la superficie es rugosa (a nivel microscópico, llenas de pequeñas "salpicaduras") y sobre todo justifica la falta de detalle en algunas partes de los sellos (pues pequeñas porciones de la superficie de los motivos debieron quedar pegadas a la matriz y, por tanto, se perdieron al arrancarlas del ánfora en el proceso de separación de ella). Una de las estampillas (Figura 4.1) fue además aplicada con escasa profundidad, aunque con cierto cuidado para que se marcase toda la iconografía de forma homogénea; poste- riormente, sin embargo, fue en parte alterada por el trazado de la incisión que marca la altura superior de las asas. En conjunto, estos datos demuestran que las marcas se imprimieron en una fase no muy avanzada del proceso de producción, entre el inicio del secado (poco después de salir del torno) y la colocación de las asas, lo que sugiere que la persona dedicada a esta tarea transitaba por las zonas clave de los talleres durante el apogeo del proceso de manufactura, marcando los ejemplares incluso antes de que estos estuvieran propiamente completos. Por otro lado, las pastas de ambas piezas sugieren el empleo de recetas algo distintas para la producción de una y otra ánfora, por lo que podría incluso presumirse que se trata de envases fabricados en talleres distintos. En cualquier caso, del mismo modo que hemos planteado para otras marcas locales, es plausible que las dos estampillas sean improntas de anillos signatarios enteramente metálicos dotados de chatones ovalados, una práctica que parece mayoritaria entre los sellos de las ánforas locales propios de los siglos IV-III a.C. (Sáez et al., en prensa).

Los motivos representados en los sellos también aportan información de gran interés sobre la sociedad de la época. Por una parte, el sello documentado sobre el fragmento de menor tamaño, parcialmente perdido por la rotura de la pared (Figura 4.1), fue inicialmente identificado como una "cabeza masculina de perfil", mirando hacia la derecha (Sáez y Ferrer, 2018: 278-279, cuadro 1). Sin embargo, su examen microscópico detallado permite ahora matizar notablemente dicha descripción genérica y clasificarlo como la representación de la vista lateral de un casco de tipo corintio. Varios detalles delatan esta adscripción, como la clara delimitación lineal del protector nasal, el remate inferior del casco (bien marcado por dos líneas) y la transición entre la parte superior (capacete esferoide) y la zona de protección de la nuca/cuello. Los protectores laterales o carrilleras se conservan sólo parcialmente, puesto que al estampar sobre la arcilla demasiado fresca la parte delantera fue arrancada de la superficie del ánfora por la matriz, por lo que sólo se observa la huella indirecta de su trazado. La línea que nítidamente separa la protección de la nuca de estas partes laterales es en cualquier caso marcada y relativamente amplia, lo que sugiere que se trata de una forma evolucionada de estos cascos, propia del periodo clásico tardío o de inicios de la fase helenística (Hixenbaugh, 2019). La iconografía por tanto 

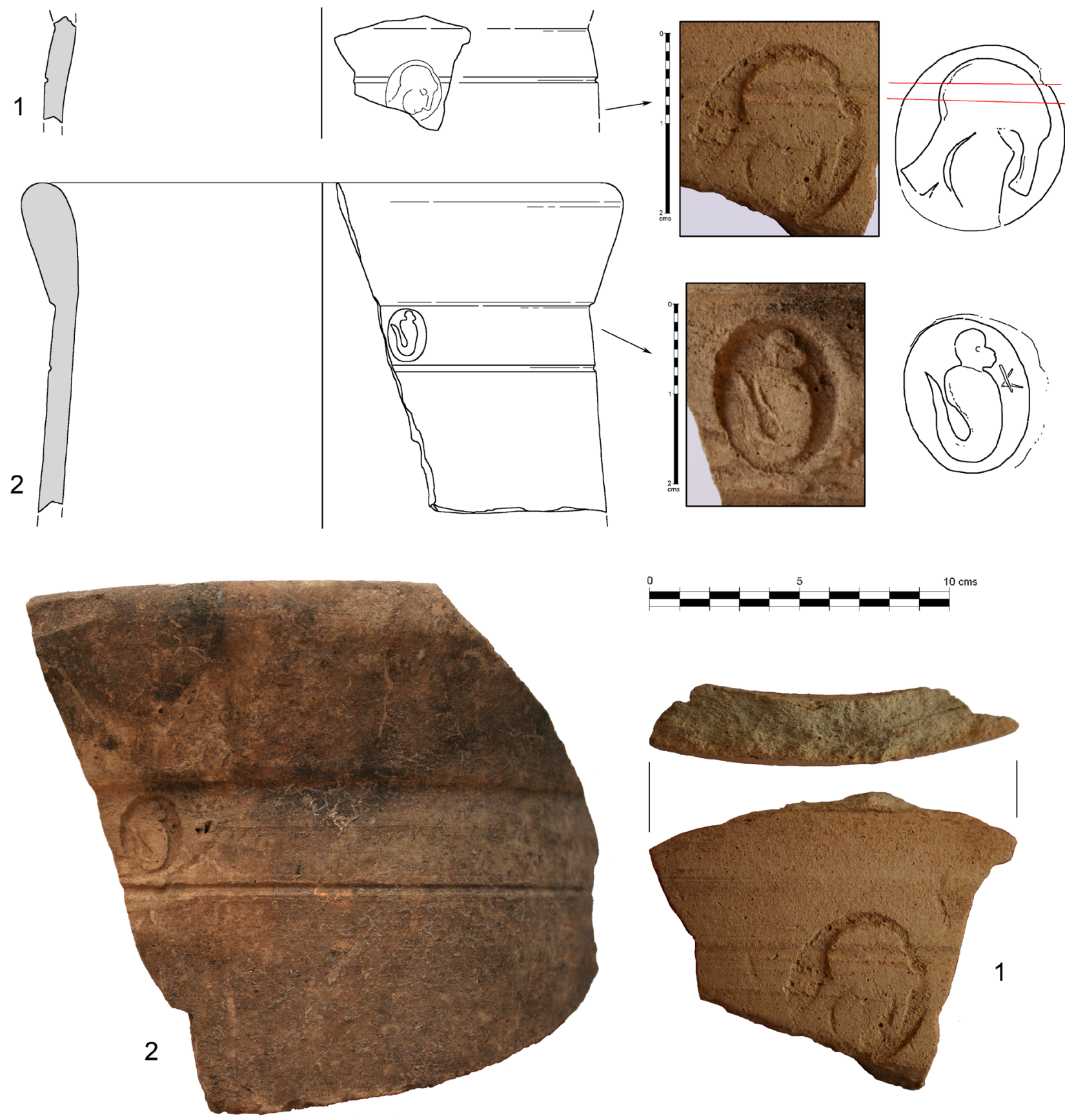

Figura 4. Ánforas del tipo T-8211 documentadas en el Nivel II del vertedero de los cuadros C1/D1, con sellos estampados sobre la parte superior del cuerpo.

se correspondería con la tipología del envase y el contexto, aunque no permite precisar la datación concreta, más allá de encuadrarla en el siglo IV o en el tramo inicial del III a.C.

No se observa la presencia de detalles adicionales añadidos al casco ni en la parte superior ni en relieve en la frente (donde es frecuente la aparición de una línea remarcando el ceño) o en los laterales, y tampoco se aprecian indicios de que el casco sea portado por ningún individuo, dando la impresión de ser una representación de este ítem sin asociarse a ningún guerrero o divinidad, como es frecuente encontrarlo tanto en los tipos monetales de la época como en bullae (por ejemplo, entre las documentadas en Cartago; Berges, 1998: 129, lám. VI.7). De hecho, parece probable que el motivo pudiera estar inspirado en tipos monetales relativamente frecuentes entre los siglos V-IV a.C., 
como los corintios (o los de sus colonias, en particular Siracusa) con representación de Atenea con casco; las dracmas acuñadas por Leucipo en Metaponto hacia 340-330 a.C.; las varias series con representación de cascos corintos/áticos de Mesembria (de finales del siglo IV a.C.); o las estáteras aúreas de Cícico con representación de un casco junto a un atún (Mani y Liewald, 2006; Wroth, 1892). En cualquier caso, se trata de un elemento de uso militar que era ya bien conocido en el occidente mediterráneo desde momentos muy anteriores, como muestran hallazgos datados entre los siglos VII-VI a.C. registrados tanto en contextos aparentemente votivos (ofrendas arrojadas a ríos o al mar, caso de los hallazgos de Huelva, Jerez o el Guadalquivir; una síntesis en Martín y García, 2018) como en tumbas vinculadas a guerreros probablemente fenicios (García et al., 2018). Por tanto, este sello abunda probablemente en la helenización formal del equipamiento bélico de los gadiritas $\mathrm{y}$, en general, de muchos componentes materiales de su cultura, como se ha puesto de relieve en los últimos años a propósito de sus prácticas culinarias (García et al., 2016; Sáez, 2020). Las relaciones de Gadir con el mundo griego, sobre todo las asociadas al comercio marítimo, han sido ampliamente constatadas para el siglo V a.C. (en particular las establecidas con Corinto; Sáez et al., 2020b); y en la necrópolis de los siglos V-IV a.C. son cada vez más abundantes los testimonios aportados por los ajuares funerarios que señalan un creciente gusto helenizado, al menos en lo que se refiere a piezas de joyería y vasos cerámicos (un ejemplo en Belizón et al., 2020). El motivo elegido para esta estampilla, cuya matriz posiblemente fue otro anillo signatario, representaría por tanto a un personaje o casa local que tendría quizá un vínculo (al menos material) con el mundo griego o con esferas culturales helenizadas y tal vez también con la actividad militar de la ciudad.

El segundo de los sellos estampados sobre una T-8211 local corresponde a una cartela oval en la cual se representó una serpiente o uraeus (Figura 4.2). La estampilla fue dada a conocer inicialmente sin asociación al envase, haciendo hincapié en el origen y posible interpretación de la figuración (Sáez y Ferrer, 2018: 298-290, fig. 6.3). Como se apuntó entonces, se trata de un motivo de probable origen egipcio pero ampliamente copiado y reinterpretado en el repertorio iconográfico fenicio desde momentos anteriores a la diáspora colonial, siendo relativamente frecuente su empleo con una función protectora y apotropaica en arquitectura, joyería o la labra de estelas, en Cartago y su zona de influencia (Fernández y Padró, 1986; Gamer-Wallert, 1978; Padró, 1985; Redissi, 1991; Vercoutter, 1945), por lo que el poseedor de la matriz que se utilizó para estampillar el ánfora gaditana -probablemente un anillo signatario- pudo utilizar este motivo con dicha función o como un emblema representativo de su vinculación con ambientes púnicos centromediterráneos u orientales. En cualquier caso, la contenida en el sello corresponde a una versión "a la egipcia" del uraeus, con el cuerpo y la cola elevados y la capucha desplegada en posición amenazante. Como en otros sellos locales, el hecho de que se estampase con la arcilla aún muy húmeda no ha permitido que se conservasen otros detalles que seguramente estarían presentes en la matriz, caso de las características del rostro. El mismo hecho impide interpretar con claridad los tenues trazos que parecen adivinarse frente al uraeus, entre su cuerpo y el borde derecho de la huella. Si estas posibles dos o tres líneas, finas y de escaso relieve, fueron en efecto parte del diseño original de la matriz, pudieron corresponder a algún elemento o icono complementario del símbolo egiptizante central (o incluso, aunque menos probablemente, a un signo o grafema, pues en determinadas condiciones de observación los posibles trazos parecerían formar una suerte de áleph esquemático).

Este motivo se inscribe en una dinámica de uso de iconografías egiptizantes bien conocida en el ámbito local, por ejemplo en la joyería metálica depositada en las tumbas al menos desde el final del siglo VII a.C., apareciendo no sólo representaciones del uraeus en medallones (Perdigones et al., 1990: 69-70, lám. XIV.2) sino también de otros motivos, como figuras hathóricas, flores de loto o "árboles de la vida" (De la Bandera et al., 2010), además de una gran cantidad de representaciones de divinidades fabricadas en pasta vítrea o fayenza. Se trata, en cualquier caso, de una iconografía que encuentra numerosos paralelos tanto en soporte metálico como en piedra (escarabeos o escaraboides y gemas) en el área púnica del Mediterráneo central, si bien no se conocen sellos de uso alfarero con esta iconografía. En el ámbito local tampoco se han identificado anillos-sello con este motivo del uraeus, aunque sí representaciones de serpientes y del oudjat (en cartela cuadrada) entre los anillos signatarios depositados como ofrendas en el santuario de La Algaida (López y Ruiz, 
2010: 277-280, fig. 5.11). En definitiva, un motivo de difícil interpretación que podría haber sido emblema de un personaje o linaje local ligados al negocio conservero-alfarero; y que podría haber sido utilizado con un mero fin apotropaico o con la intención (quizá añadida) de destacar una conexión con los ambientes púnicos de Ibiza o el Mediterráneo central. Ambos sellos apuntan por tanto a influencias mediterráneas en sus iconografías, con fuentes quizá comunes si consideramos que el casco representado en el sello de la figura 4.1 habría sido ampliamente utilizado también por los ejércitos púnicos de la época, especialmente en el ámbito centro-oriental del Mediterráneo.

Los envases de importación también configuran en conjunto un nutrido grupo, con una notable heterogeneidad interna en cuanto a tipologías y procedencias. Destaca la presencia en este contexto basal de la Fosa 5 de individuos del tipo T-11210 y sobre todo $\mathrm{T}-12111$ fabricados en otros centros de la región del Estrecho, probablemente tanto en su vertiente mediterránea ibérica como mauretana. Asimismo, un numeroso conjunto de importaciones corresponde a envases tipo Tiñosa (Ramon T-8112) y Pellicer D (Ramon T-4225), procedentes tanto de la campiña xericiense como de las áreas del Guadalete y del Bajo Guadalquivir. En menor número también se recuperaron algunos ejemplares de ánforas ibéricas levantinas, una T-8111 ebusitana y varias ánforas griegas (orientales y magnogrecas). Sin embargo, interesa destacar la recuperación de varios contenedores de pastas tunecinas, envases de morfología acilindrada y bordes planos desarrollados al interior que en algunos casos parecen responder casi al esquema de las T-5231, pero que en otros, por la tendencia más curvada de la pared o por la morfología del incipiente pivote, parecen acercarse más al T-4215, precursor del anterior. Esta combinación, también documentada en algunos depósitos de la segunda fase de Puerto-19 (Sáez et al., 2020a), parece apuntar a un momento transicional entre ambos modelos en los talleres cartagineses productores, una etapa que podemos situar actualmente en la primera mitad del siglo III a.C. (Ramon, 1995: 288-289). Se trata, en cualquier caso, de elementos todos ellos probablemente vinculados al abastecimiento alimentario cotidiano de los trabajadores de las instalaciones conserveras, que consumían aceite, vino, conservas y quizá otros productos de Turdetania, de otros puertos del Estrecho y del área centromediterránea (tanto griegos como púnicos).
Destaca la abundancia de sellos estampados sobre estas importaciones anfóricas, ya puesta de manifiesto en otros contextos vinculados a la necrópolis insular tardopúnica (Zamora y Niveau de Villedary, 2008; Zamora, 2010). En el caso del nivel 2 de la Fosa 5, esta abundancia se manifiesta en dos individuos de cuerpos acilindrados con morfometrías muy similares que portaban sellos idénticos de matriz circular colocados en la parte superior de las asas (¿siendo quizá contenedores de una misma partida?) (Figura 5); además otra estampilla, también de perfil circular, pero ilegible, se halló estampada sobre el arranque inferior del asa de una T-4215 (Figura 6). A través de al menos las dos primeras estampillas tenemos pues testimonio del uso repetido de una misma matriz, con la que quizá un mismo individuo selló dos envases distintos, pero con toda probabilidad provenientes de un mismo taller (o al menos de una misma área productora) presumiblemente del entorno de la propia Cartago, a tenor del examen macroscópico de su morfología y pastas. En ambos casos la inscripción (lamed-lamed) no parece estar aludiendo a un antropónimo abreviado, sino que debió relacionarse con otros aspectos del control y cuantificación de la producción en los alfares cartagineses del periodo (véase una más amplia discusión, con paralelos, en el apartado 4.1).

En cuanto a los elementos de vajilla barniza$\mathrm{da}$, comunes y de cocina, es necesario señalar que constituyen en conjunto más de $2 / 3$ del depósito por número de individuos, teniendo un protagonismo aplastante las producciones de los alfares gadiritas frente a las importaciones, que en este nivel -pero siempre de forma localizada- presentan una sugerente diversidad, formando parte de casi todas las categorías. El barniz rojo local ("de tipo Kuass") en sus diferentes versiones y variantes evolutivas es, con mucho, la más representativa en cuanto al servicio de mesa barnizado se refiere (platos de pescado, de borde moldurado, cuencos de borde entrante, copas carenadas, pequeñas jarras, etc.). Entre estas piezas de vajilla local debemos incluir un perfil completo correspodiente a un cuenco de borde entrante, poco profundo y de pie anular cuidado ("bífido"), que se encuadra en la forma IX-B de Niveau de Villedary (2004: 7178, fig. 17), que presenta en la parte exterior de la base un grafito inciso post-cocción en forma de aspa (véase el comentario específico más adelante, apartado 4.2; Figura 7.1). 

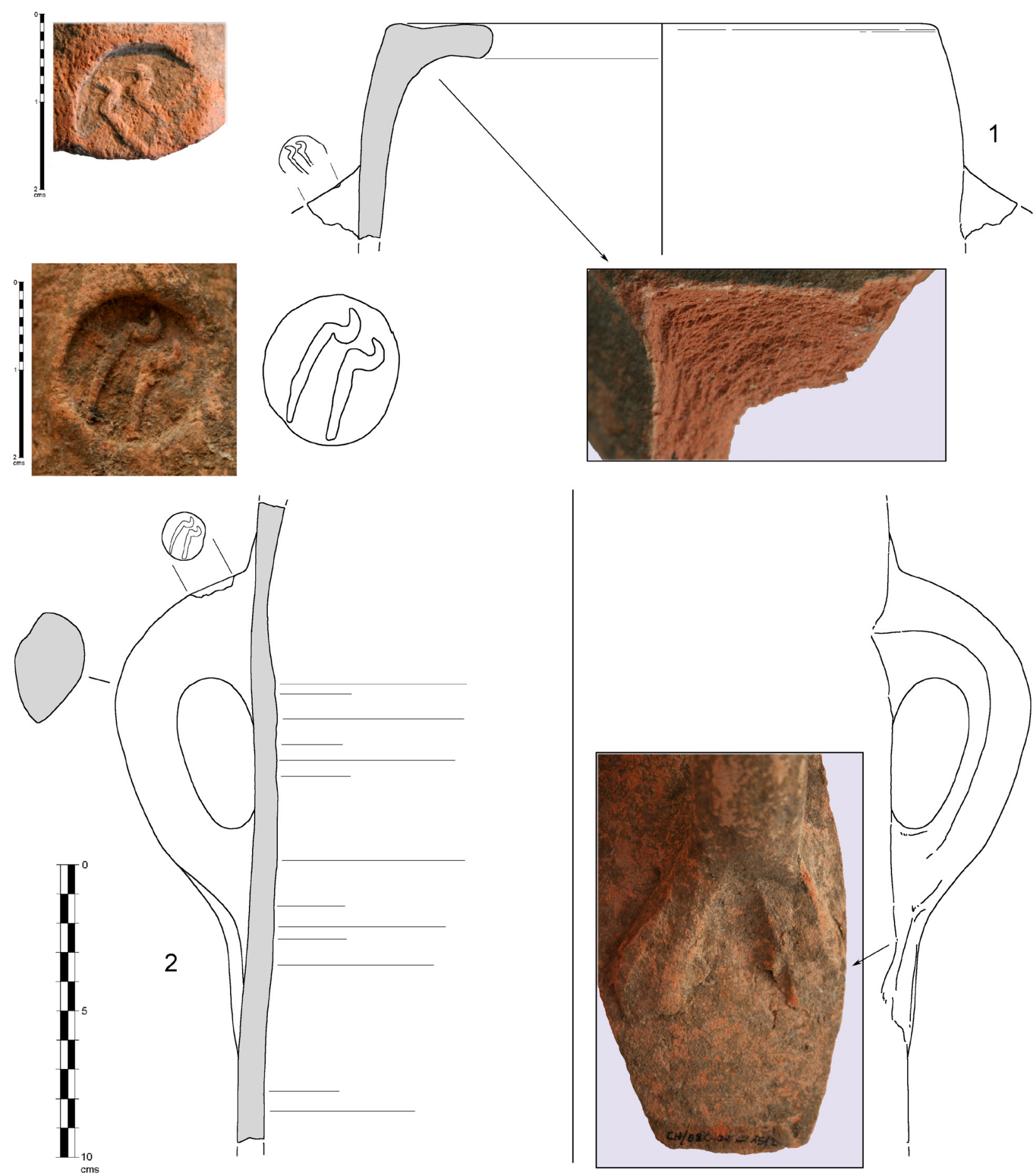

Figura 5. Ánforas cartaginesas con una morfología cercana al tipo T-5231, en ambos casos portando sellos idénticos colocados en la parte superior de las asas, procedentes del Nivel II del vertedero de los cuadros C1/D1. En los recuadros se muestran detalles de la pasta del individuo 5.1 (arriba) y de la particular morfología del arranque inferior del asa de 5.2. 


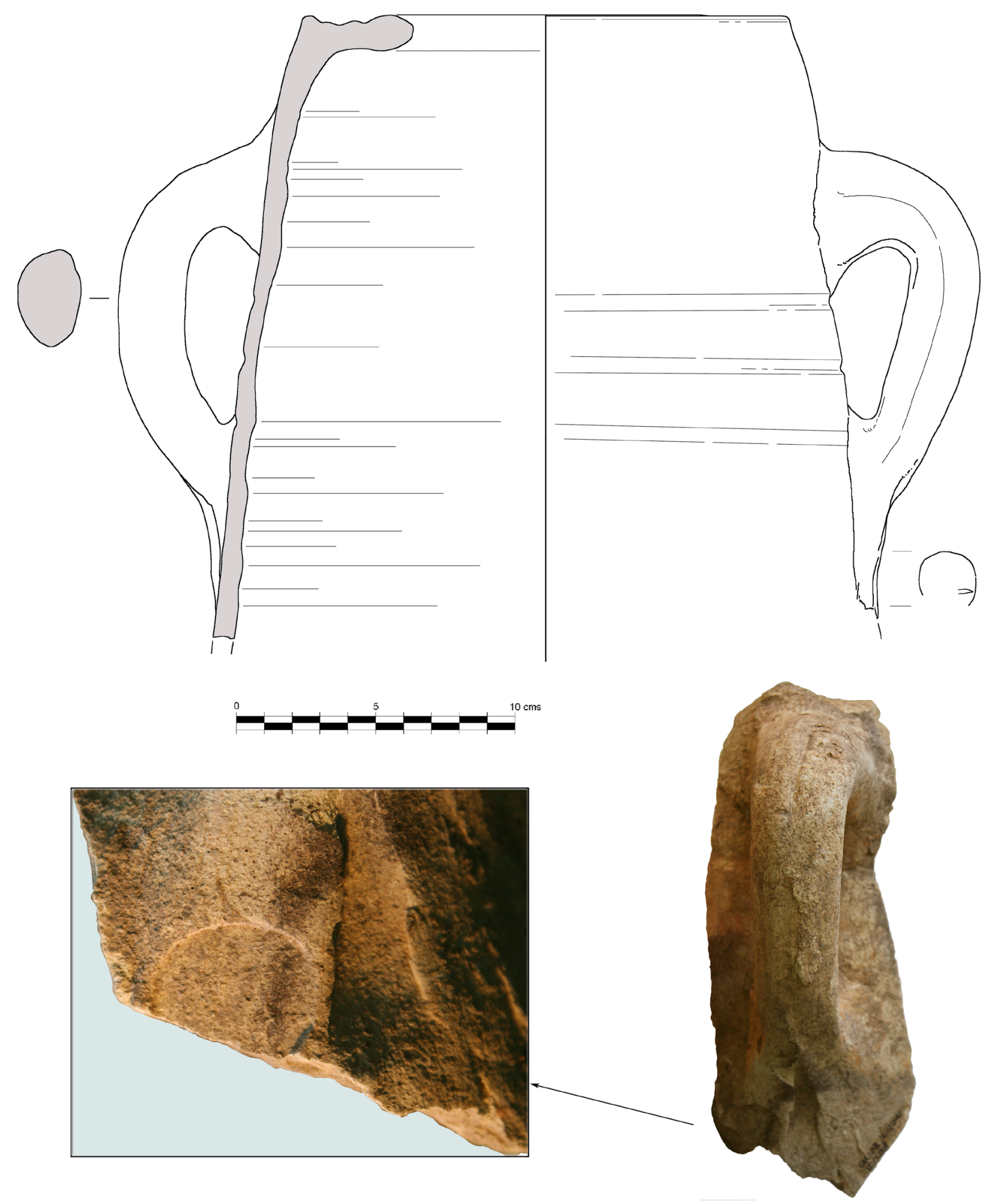

Figura 6. Cuarto superior de un ánfora cartaginesa del tipo T-4215 con un sello ilegible estampado en la zona baja del asa del Nivel II del vertedero de los cuadros C1/D1. Puede observarse la similitud en la forma de colocación del asa respecto del individuo representado en la figura 5.2. 
La vajilla barnizada se completa con un significativo grupo de importaciones de barniz negro ático (outturned rim bowls, fish-plates, incurving rim bowls, skyphoi, lécitos y lucernas), propias de momentos tardíos del siglo IV a.C. Asimismo, están presentes en el contexto un buen número de piezas de pasta gris, de fabricación local, que también se inspiran en estos repertorios barnizados. Finalmente, un tercio de los individuos del estrato corresponden a formas locales sin tratamiento, ollas y cazuelas, y puntualmente a importaciones de tinajas pintadas (una forma turdetana y otra quizá de origen mauretano). En definitiva, se trata de un numeroso y variado conjunto cerámico que está dominado cuantitativamente por las producciones locales, tanto en el ámbito de los envases de transporte como de las vajillas de mesa o útiles multifuncionales, lo que sugiere que los trabajadores del edificio conservero dependían de los talleres locales para su autoabastecimiento aunque tenían también acceso a determinadas importaciones alimentarias y de vajilla (ática).

El nivel 1 corresponde a un segundo horizonte de descargas más recientes depositadas en el interior de la Fosa 5, cuya distinción sutil del nivel inferior podría deberse simplemente a un mayor aporte de material orgánico. De cualquier forma, la composición material del nivel parece repetir en general las proporciones y procedencias mostradas por el horizonte inferior, con unos parámetros cronológicos también muy similares. Las ánforas constituyen una parte muy destacada del material del depósito (más de 1/4 del total cerámico), predominando nuevamente las producciones gadiritas, y entre ellas las T-11210, T-12111 y sobre todo T-12111/2 y T-8211. Como en el nivel inferior de la Fosa 5, las importaciones anfóricas corresponden mayoritariamente a envases turdetanos Pellicer D y del tipo Tiñosa, además de, en menor medida, a un limitado grupo de ánforas T-12111 de fabricación regional y otras griegas ("samias" y corintias) junto a T-4215 de pastas tunecinas.

Una de las T-8211 locales portaba una estampilla no grafemática sellada a la altura de la acanaladura bajo el labio, de morfología casi circular enmarcando la representación de un ave de perfil, probablemente una paloma (Figura 7.2). Como en los casos ya descritos para el Nivel 2, el envase presenta la típica estructura de diámetro amplio (más de $20 \mathrm{~cm}$ en el labio) y líneas simples en la transición borde-cuerpo, con una única incisión practicada precocción señalando la zona superior de colocación de las asas. La estampilla se colocó precisamente a esta altura del cuerpo y, como en el caso del casco de tipo griego (Figura 4.1), la incisión la alteró superficialmente, dejando un trazo de escasa profundidad pero claramente perceptible. Aunque el estampillado con la arcilla húmeda se llevó a cabo con algo más de cuidado en esta ocasión, apenas son perceptibles (incluso tras observar detenidamente el sello con lupa binocular) algunos detalles, como una línea o pequeño resalte en la zona central del cuerpo que parece dibujar la superficie del ala. Como en los restantes ejemplos de improntas locales se realizó con una matriz de perfil oval sin gráfila, con una superficie horizontal y con el motivo figurado ocupando gran parte de la zona central del campo. Todo ello sugiere de nuevo que nos encontremos ante la impresión de una anillo signatario metálico.

Este tipo de joyas con motivos zoomorfos se ha documentado profusamente en contextos muy relacionados con la bahía gaditana como el santuario de La Algaida, entre cuyas ofrendas se localizan varios ejemplos con representaciones de una o varias aves (López y Ruiz, 2010: 277-280, fig. 5.8). Se trata por tanto de un motivo iconográfico conocido en el repertorio local que parece aludir a temáticas religiosas, pues la paloma es un motivo frecuentemente representado en estelas del área cartaginesa en relación con la esfera cultual y funeraria y con divinidades púnicas como Tanit (Sáez y Ferrer 2018: 290-291). Precisamente de La Algaida procede otro sello sobre ánfora gaditana (quizá también una T-8211 o una T-9111), este en cartela circular, que parece también representar a un ave de perfil, con unas dimensiones y composición general muy similares a las del sello de Los Chinchorros (aunque se trata de un cuño/anillo distinto; Ferrer, 1995). La representación de aves no parece ser algo frecuente en los sellos cartagineses de la época, al menos a tenor de la información publicada (Ramon, 1995: 578-584), aunque sí ha sido documentada en el caso de sellos anfóricos ibicencos datados en el siglo II a.C. (Ramon y Zamora, 2019), cuya estructura e iconografía no parecen tener relación con nuestro caso. Al igual que en relación a los sellos localizados en envases del Nivel 2 cabe preguntarse por el significado de este ave y por la conexión que el poseedor de la matriz habría tenido con la producción cerámica y de conservas de pescado en la transición entre los siglos IV-III a.C.

En los elementos de vajilla barnizada ("de tipo Kuass") y de pasta gris del nivel 1 se observa un 

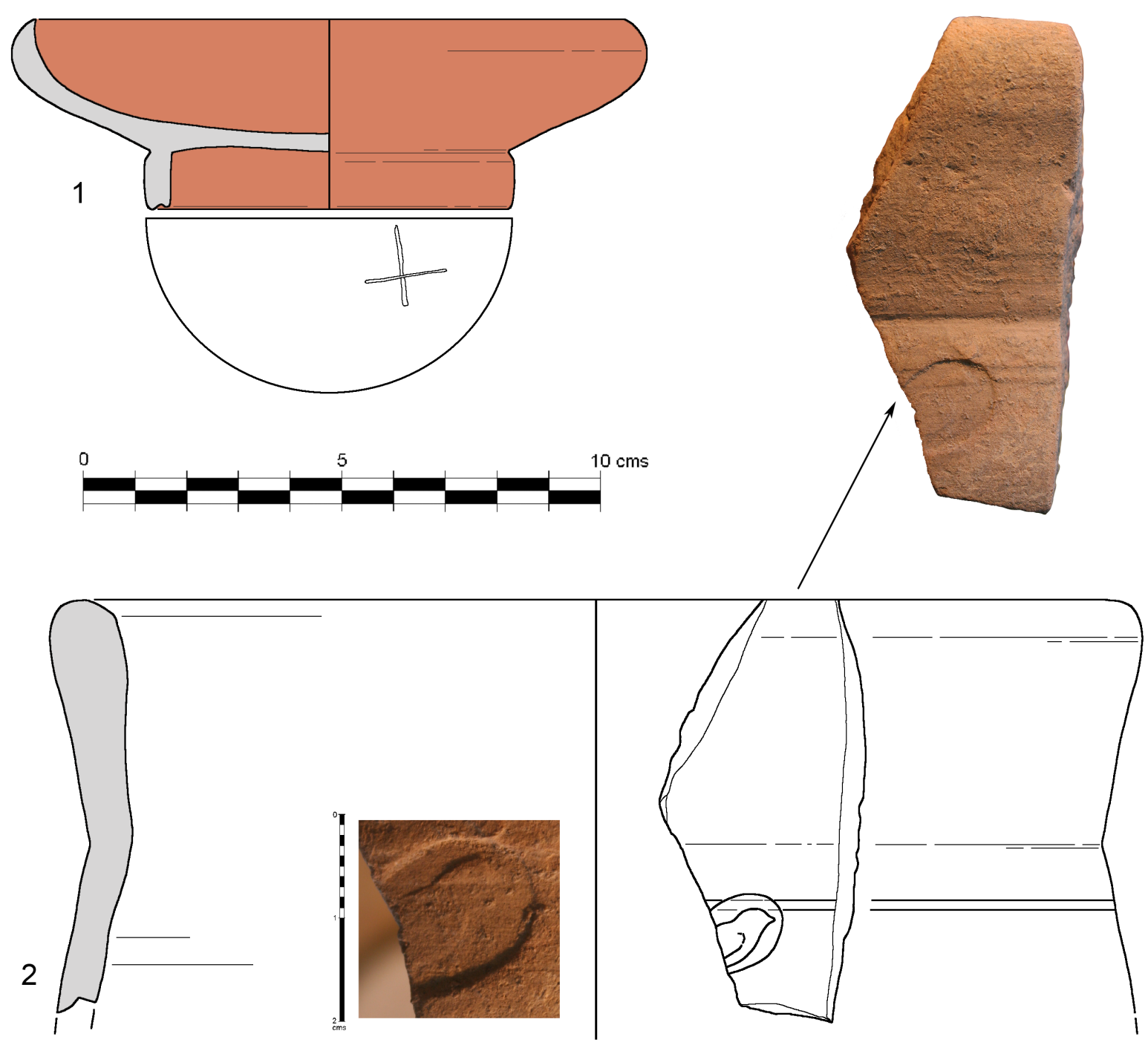

Figura 7. Cuenco de cerámica de engobe rojo "de tipo Kuass" con grafito postcocción en forma de aspa (1), del Nivel II del vertedero de los cuadros C1/D1; y fragmento de ánfora local T-8211 sellado con una impronta en forma de ave inscrita en una cartela oval (2), del Nivel I del vertedero de los cuadros C1/D1.

comportamiento similar al descrito para el nivel 2 en cuanto a su composición tipológica y su importancia cuantitativa, de nuevo acompañadas de cerámica de barniz negro ática. Las formas comunes -enteramente de producción local-suponen en conjunto otra cuarta parte del total cerámico del nivel, repitiendo en líneas generales el mismo repertorio del nivel 2. Por su parte, la cerámica de usos culinarios fabricada con pastas comunes refractarias cuenta en este nivel con un protagonismo porcentual mayor que en el precedente, si bien las formas representadas siguen siendo prácticamente las mismas (ollas globulares, otras del gru- po GDR-12.3.0 y numerosas cazuelas carenadas).

Tomando como referencia principal el registro anfórico y la vajilla barnizada, el inicio del uso de la fosa debemos situarlo en un momento coetáneo a la Fosa 7 (cuadro C4), en torno a mediados del siglo IV a.C., recogiendo probablemente el nivel inferior elementos residuales circundantes (también presentes en menor número en el nivel 1). La utilización del gran vertedero parece que se mantuvo al menos hasta mediados del siglo III a.C., sin que sea posible determinar con claridad el momento de abandono y amortización del depósito. La tipología de las ánforas mayoritarias, los servicios de 
vajilla locales presentes en ambos niveles, la presencia testimonial de T-9111 muy iniciales (o de T-5231 en el caso de las importaciones) y la significativa presencia de la vajilla de pasta gris, no aconsejan extender la datación del uso de la fosa más allá del tercer cuarto del siglo III a.C., pues se trata en todos los casos de rasgos que difieren de los componentes habituales de depósitos bien fechados en el tramo final de la centuria, como los de Doña Blanca - Las Cumbres (Niveau de Villedary y Ruiz, 2000) o en el alfar de Torre Alta y otras localizaciones insulares (Sáez, 2008). Los sellos documentados sobre individuos locales del tipo T-8211 se inscriben por tanto en las series estampilladas más antiguas, probablemente anteriores a la etapa bárcida, un horizonte en el que también deben situarse las estampillas sobre individuos de cuerpos acilindrados y fábrica tunecina.

\subsection{Los niveles de amortización del horno y su entorno (cuadro D5)}

La estructura se construyó probablemente sobre algunos muros en desuso y parcialmente amortizados, aunque la interpretación cronológica y funcional del horno resulta muy compleja debido al alto grado de arrasamiento de toda la zona y a la inexistencia de conexiones estratigráficas nítidas con las estructuras o suelos circundantes. Parece probable que su momento final de actividad no estuviese muy distanciado de su propia construcción, dado que no se observan huellas de rubefacción, vertederos anexos $\mathrm{u}$ otros indicios que sugieran que la estructura tuviese un intenso y prolongado periodo de utilización (como sí se ha identificado en el caso de numerosos hornos cerámicos tardopúnicos locales; Sáez, 2008). Sobre su funcionalidad, la planta circular dotada de corredor de alimentación recuerda vivamente a los citados hornos alfareros, si bien la estructura carece de recubrimiento de plaquetas o adobes, de suelo y -sobre todo- de un pilar o columna central que soportase la parrilla. Tampoco se hallaron restos de ésta, ni tampoco fragmentos de adobes cocidos o acumulaciones de escorias deformadas, elementos normalmente numerosos y frecuentes en los lugares donde se fabricaron cerámicas, por lo que la relación de la estructura con la alfarería parece poco probable. Se ha valorado también la posibilidad de que pudiera tratarse de un horno en proyecto, que no llegase a entrar en funcionamiento, o quizá una piroestructura vinculada a la produc- ción de cal destinada a los suelos y recubrimientos de mortero (cocciopesto) propios de las fases más tardías del saladero. Sin embargo, la ausencia de pruebas de combustiones reiteradas a altas temperaturas, así como de materiales quemados o térmicamente alterados, tampoco permiten dilucidar si pudo ser esta su función.

En cualquier caso, la amortización interna del horno es en realidad el único contexto que aporta indicadores cronológicos significativos (al margen de la información indirecta que nos aporta su propia ubicación). Los materiales diagnósticos recuperados en el interior del horno $\mathrm{H}-1$, muy escasos, señalan que puede asociarse al horizonte de abandono generalizado del saladero (el evidenciado por el relleno de los diversos ambientes del edificio principal) y al contexto cercano al brocal del Pozo PZ-5 (véase apartado 3.3). El relleno corresponde a un nivel de arenas pardas asociado a un número de restos diagnosticables muy escaso, junto a los cuales se recuperaron algunos amorfos anfóricos locales, entre los cuales se identificó la presencia de algunas T-12112. En cuanto a los materiales de importación, las formas documentadas se reducen a tres individuos de barniz negro itálico: una L1 de procedencia calena con un grafito en forma de aspa en la base (Figura 8.1), un fondo de pátera decorado con ruedecilla gruesa y estampillas en forma de hoja, y otra base de atribución indeterminada en "campaniense A". Se trata por tanto de un conjunto muy limitado, aunque en todos los casos apuntando hacia una datación en la segunda mitad del siglo II a.C., quizá con más probabilidad en un momento muy tardío de la centuria o-si dichos materiales pudieran considerarse residuales-incluso en los inicios del I a.C.

De entre el conjunto destaca la presencia de dos marcas, muy diferentes entre sí. Se trata, por una parte, de un grafito inciso en la parte inferior del cuenco, que no parece ser un signo grafemático pero que en cualquier caso sí se relaciona con la costumbre de marcar los ítems, bien dentro del proceso productivo o comercial, bien como distinción de propiedad (véase el comentario específico en el apartado 4.3). Por otro lado, resalta entre el conjunto de materiales de pasta local la recuperación de un tercio central de ánfora local T-12112 (Figura 9) que portaba una estampilla circular en la zona baja del cono superior, en la zona media del cuerpo. La pieza presenta la habitual morfología acilindrada, con una parte superior del cuerpo de escaso diámetro que se ensancha suavemente 

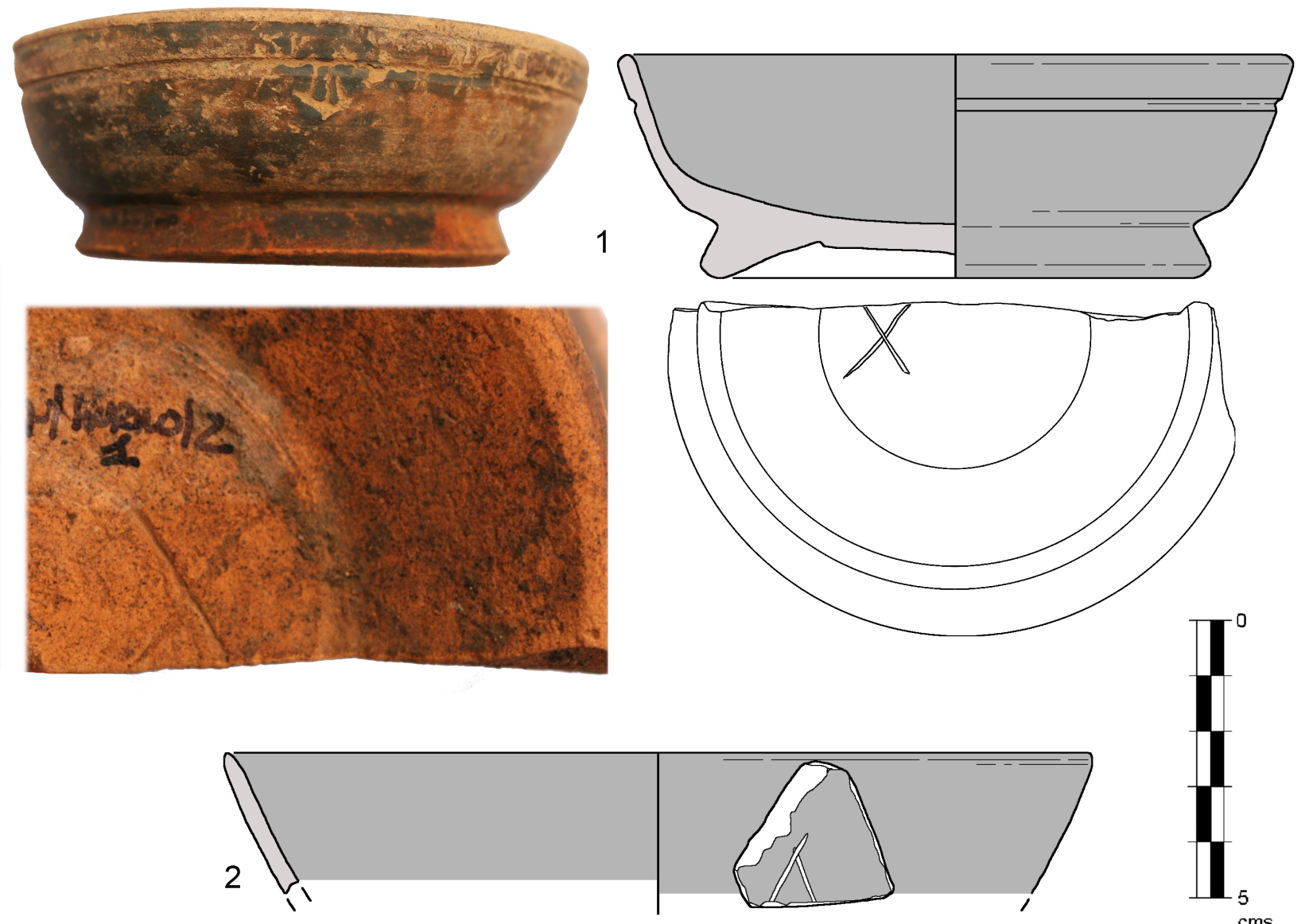

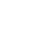
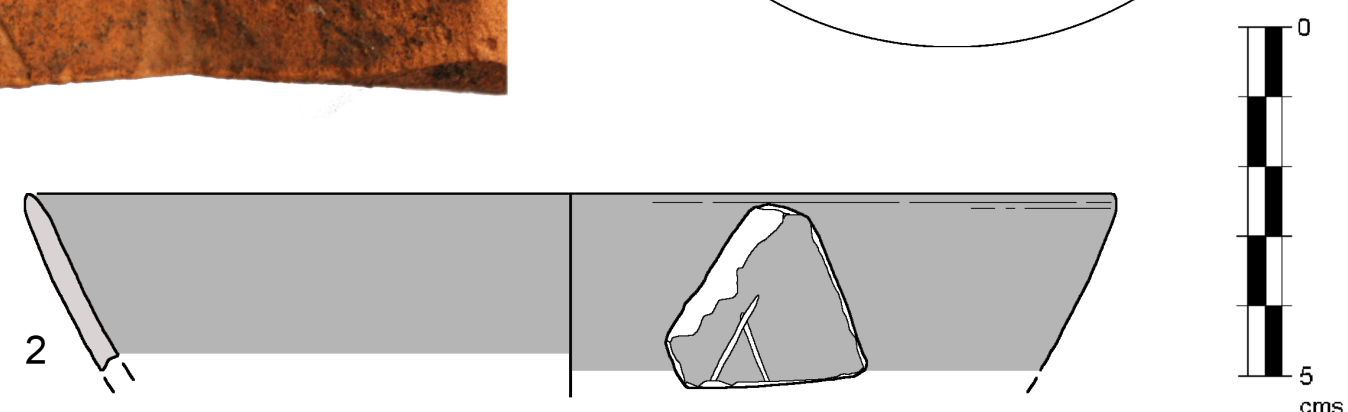

Figura 8. Cuencos de barniz negro itálico con grafitos incisos post-cocción documentados en el horno del cuadro D5 (1) y en los niveles superiores de amortización del horno y los muros adyacentes (2).

para la zona del diámetro máximo. No se observan huellas muy evidentes al exterior de acanaladuras o estrías de torneado, o de las zonas de unión de las piezas que componían el ánfora, aunque en general el envase tiene un acabado poco cuidado y paredes gruesas, lo que es habitual en estas manufacturas tardías de la serie (Sáez, 2018). Su perfil y características técnicas encajan por tanto con la cronología sugerida por la vajilla itálica, apuntando a la segunda mitad o último tercio del siglo II a.C.

La marca, cuya iconografía es por ahora un unicum en el catálogo de sellos anfóricos locales, aporta también datos muy sugerentes sobre los sellos anepígrafos que aún se estampaban en este periodo en los alfares locales. Como en casos anteriores, se trata de una marca con una morfología oval, que dejó una impronta horizontal relativamente profunda (más en un lado) aunque incompleta, posiblemente también vinculada al uso de un anillo signatario metálico como matriz. El motivo no ofrece una lectura unívoca, pues en un principio pensamos, guiados por paralelos del repertorio local, que podría tratarse de una variante de los sellos que contienen el denominado "signo de Tanit" (Sáez y Ferrer, 2018: 280-282), ampliamente utilizado entre las producciones de T-12112 de Torre Alta. Sin embargo, un examen más detallado y detenido de los trazos del motivo permite proponer su identificación como la representación esquematizada de un ancla. Las "uñas" de la zona inferior presentan una morfología infrecuente (inclinados los brazos hacia abajo), normalmente sólo asociada a las anclas enteramente hechas en hierro y datadas más tardíamente (tipo E de Kapitän, 1984). Pero en la parte superior se advierten con claridad una argolla y los dos brazos del cepo, que estarían unidos al vástago vertical central de madera. El posible cepo no es más que un trazo lineal que ensancha levemente en su centro, lo que no permite determinar si la fuente de inspiración sería un elemento pétreo o de plomo, aunque dada la cronología de la pieza cabe apostar 

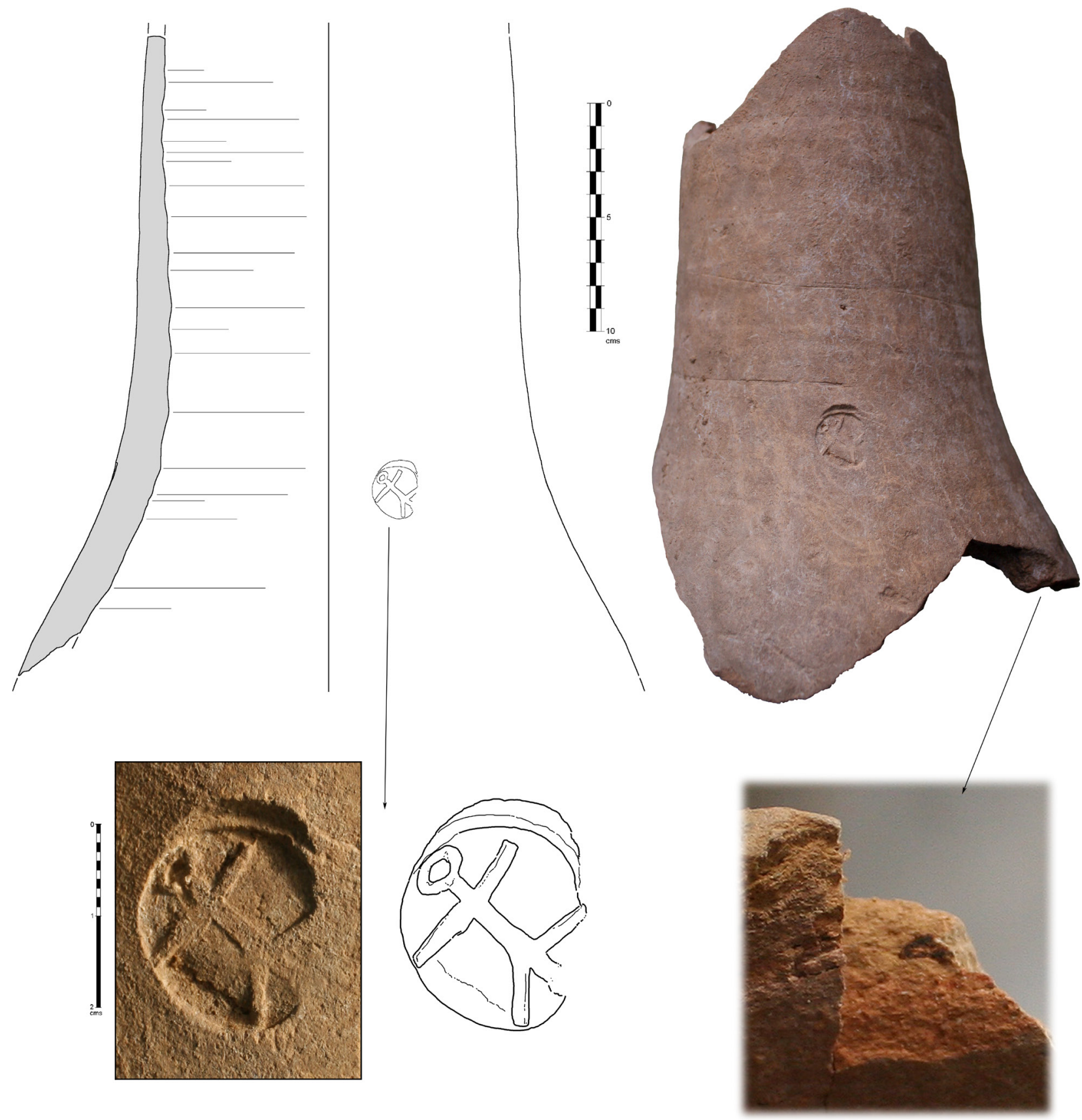

Figura 9. Ánfora de fábrica local del tipo T-12112 con impronta sellada en la parte baja del cuerpo. En el recuadro (abajo dcha.) se representa detalle macroscópico de la pasta del envase.

por la segunda opción (Tipo III de Haldane, 1986), dado que entre los siglos II-I a.C. este tipo de elementos de ancla se habían generalizado en el Mediterráneo (nótese que se ha relacionado con un posible armador gaditano de esta época un cepo de plomo documentado en el pecio de La Chrétienne M2, en el sur galo; Briquel-Chatonnet, 2005; Luaces y Sáez, 2019). Se trataría de la primera representación de un ancla entre este tipo de im- prontas, que no es particularmente frecuente ni en la glíptica ni entre los tipos monetales mediterráneos de época clásica-helenística (Votruba y Artzy, 2016), pero que encuentra un paralelo relativo en un grafito inciso sobre la base de una pieza de vajilla documentada en la zona portuaria de La Caleta (en la calle Gregorio Marañón; Blanco, 1991). En cualquier caso, este motivo náutico se puede relacionar con otras muchas iconografías frecuentes 
entre los sellos anfóricos locales del siglo II a.C., entre las cuales no son pocas las relacionadas con la pesca atunera, la fabricación y envasado de conservas y ánforas, así como otros aspectos relativos a la importante actividad comercial marítima que era uno de los pilares económicos de la ciudad y de sus élites (es decir, de los poseedores de los anillos signatarios y los impulsores del negocio salazonero).

En el entorno del horno $\mathrm{H}-1$ se documentaron varios muros pertenecientes al menos a dos o tres espacios diferenciados, anteriores a la instalación de la piroestructura en este punto. Los materiales recuperados en el estrato que amortizaba la zona, tanto el horno como los restos muy maltratados de los muros circundantes, incluían tanto material residual (squat lekythos ático, plato de barniz rojo local, variantes iniciales de las cerámicas "tipo Kuass" gaditanas, ánforas Pellicer D antiguas, etc.) como otros que parecen relacionarse con el mismo horizonte final del saladero y de amortización del horno (cerámica de cocina y barniz negro itálico, esencialmente formas L36, L55, L5/7 y L27). Uno de estos boles de paredes rectas de la forma L27 presenta una marca incisa en la cara externa (Figura 8.2), aunque desafortunadamente se trata de un fragmento de pequeño tamaño muy incompleto que no permite una interpretación clara de los trazos incisos.

\subsection{El pozo PZ-5 (cuadro C14)}

El conjunto de ánforas localizadas junto al Pozo 5 , en el cuadro C14, que ya mencionamos en apartados anteriores, proporciona sin embargo una fotografía muy específica sobre la fase final de uso del saladero y de los espacios circundantes al edificio. Se trata de cinco individuos prácticamente completos que fueron abandonados junto al brocal del pozo y agrupados, quizá tras finalizar su vida activa o en un proceso vinculado al cese definitivo total de la actividad en las instalaciones artesanales cercanas. Es posible que fuesen elementos que ya habían perdido tiempo atrás su función primaria (el transporte) y hubiesen sido reutilizados para alguna otra labor a desarrollar en el entorno del propio pozo, bien como contenedores, como filtros / embudos u otras menos evidentes.

Las ánforas locales presentes destacan por estar en minoría en el contexto, cuya composición ilustra en cierta forma las principales modificaciones en los patrones de recepción de alimentos en- vasados en ánforas del periodo. Entre las producciones de la bahía gaditana destaca una T-12112 (Figura 10) que porta una estampilla circular situada en la zona baja del cono superior, que presenta un par de posibles letras ocupando la zona central junto a las que nada lo que parece un delfín (aunque este conserva un escaso detalle y relieve). Desde la perspectiva tipológica el envase presenta una morfología típica de las fases iniciales de desarrollo de las T-12112 propias de mediados del siglo II a.C., con un cuerpo muy acilindrado, carena de transición al cuerpo muy suavizada, múltiples acanaladuras exteriores de torneado que denotan un acabado poco cuidado, una carena de la transición a la espalda apenas aristada, asas muy pequeñas adosadas al cuerpo y un borde casi vertical dotado aún de la característica incisión practicada precocción. Se trata por tanto de rasgos tipológicos y tecnológicos ampliamente reconocidos en numerosos talleres alfareros locales de la época (Sáez, 2008, 2018). Resulta sin embargo menos frecuente, aunque muy informativa, la presencia de rebabas de arcilla sobre la parte superior del borde, del mismo color y consistencia que la pasta de la propia ánfora, lo que sugiere que el sistema de hermetización original pudo contar con una parte de material orgánico (madera, corcho, tela) que fue posteriormente macizada con una capa de arcilla fresca. Se trata de un dato importante dada la crónica carestía de informaciones sobre los elementos empleados para taponar las ánforas gaditanas tardopúnicas.

El motivo estampillado sobre la zona central del cuerpo del ánfora también resulta de gran interés. En el caso de la figura del delfín, se trata de una variante iconográfica de un motivo que es ya conocido en el marco del relativamente extenso catálogo de marcas anfóricas gadiritas, contándose al menos dos paralelos sellados sobre anforillas T-9111 recuperadas en aguas de La Caleta (Higueras-Milena y Sáez, en prensa) y en estratos de la primera mitad del siglo II a.C. del alfar de Torre Alta (Sáez et al., 2016; Sáez y Ferrer, 2018: 292-293, fig. 7). Sin embargo, en ambos casos se trata de una matriz distinta, con el motivo marino situado en la zona central y una cartela de morfología casi cuadrangular, de menor tamaño, y cuya utilización dejó una impronta con una superficie cóncava en la cual resaltaba en relieve un pequeño delfín, sin asociación a otros elementos o signos. En el caso de la marca de Los Chinchorros, el delfín ocupa deliberadamente una mitad del espacio 


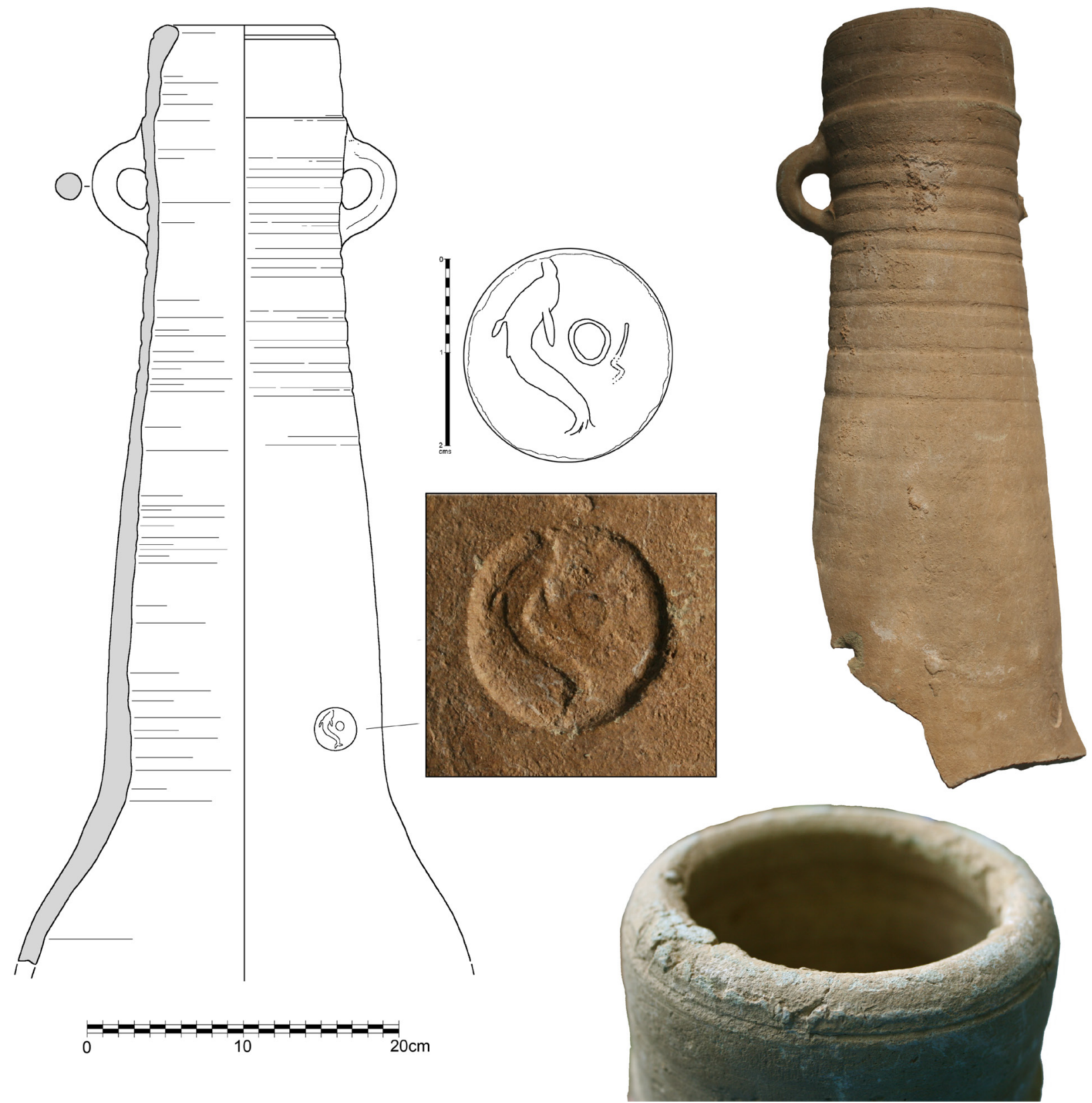

Figura 10. Dos tercios superiores de un contenedor local del tipo T-12112 documentado junto al brocal del Pozo 5 en el cuadro C14, con sello que combina un delfín con posibles signos epigráficos. Abajo (dcha.), detalle de la boca del ánfora, en la cual se observan rastros del posible sistema de hermetización con arcilla.

total, la cartela es acusadamente circular, y el volumen y detalle de la figura es claramente mayor, con una impronta con una superficie horizontal homogénea. En el caso de los sellos de Torre Alta y La Caleta es probable que se tratase de la misma matriz, un anillo signatario dotado de una gema tallada con superficie convexa, que pudo ser ocasionalmente utilizada como sello alfarero; sin embargo, el caso de Los Chinchorros corresponde a otra matriz, probablemente otro anillo-sello pero con chatón circular metálico, plano y sin gráfila, el cual fue concebido desde el inicio para portar tanto esta figuración como los signos -aparentemente grafemáticos- que se observan en la parte central de la impronta (respecto a la interpretación de dicha posible inscripción, véase punto 4.5).

Se trata, en cualquier caso, de una iconografía (la del delfín nadando de perfil) que estaba ya bien fijada en el ámbito local desde momentos anteriores, a tenor de su utilización en anillos signatarios arcaicos como el documentado en la estructura monumental anexa a la Casa del Obispo (Perea et 
al., 2004) o en otros de bronce, más tardíos, recuperados en el santuario de La Algaida (López y Ruiz, 2010: 275-280, fig. 7.23, acompañado de un tridente). A este respecto destaca sobre todo su aparición en los reversos de algunas series de acuñaciones gadiritas (Alfaro, 1988) y también como "tipo" de algunas de las contramarcas más frecuentemente labradas sobre el numerario tardío gaditano (Arévalo, 2006, 2010). En concreto, estos delfines de los sellos anfóricos locales parecen tener una conexión con las contramarcas de los tipos 2 y 3, documentadas con relativa frecuencia sobre monedas locales de la Serie VI y otras anteriores circulantes sobre todo durante los siglos II-I a.C., lo que sugiere una posible contemporaneidad de sellos/anillos, iconografías monetales y contramarcas, así como el hecho de que el delfín debió ser un motivo ya en auge en la etapa de romanización de la ciudad anterior a la municipalización y al patronazgo de Agripa.

Junto al ánfora T-12112 sellada se documentó en un estado muy fragmentario una mitad central probablemente perteneciente a una T-8211 tardía, también de fabricación local, un tipo escasamente representado en otros contextos del saladero. Las ánforas de importación son por su parte tres: una mitad superior de una T-8132 ebusitana, una mitad inferior de una grecoitálica tardía de pasta itálica vesubiana y casi los $2 / 3$ superiores de un individuo cartaginés del T-7421 o más probablemente T-7431. Todas las formas de este curioso grupo, más aún en asociación directa, parecen apuntar a su amortización conjunta hacia el tercer cuarto del siglo II a.C., aunque una datación basada en la propia tipología de las ánforas no parece poder considerarse definitiva ante la posibilidad de eventuales fenómenos de larga perduración en uso o de reutilización de los envases. En cualquier caso, se trata de un contexto que parece relacionarse con la amortización definitiva del pozo anexo y, como antes señalamos, también con los últimos momentos de utilización de las instalaciones conserveras situadas al norte.

\section{Estudio epigráfico de los hallazgos}

\subsection{Estampillas sobre ánforas cartaginesas (fosa de los cuadros C1/D1, Nivel 2) [Figura 5]}

Como señalamos anteriormente, se trata de dos individuos de cuerpos acilindrados que portaban sellos idénticos colocados en la parte superior de las asas. Las dos improntas (ambas profundas y claras, una de ellas conservada en modo fragmentario) corresponden a una misma matriz, de perfil prácticamente circular. Esta presentaba únicamente dos grafemas del alfabeto fenicio, incisos con gran claridad y profundidad, en trazos anchos pero precisos, delineados incluso con variaciones de grosor de tipo caligráfico. Así se aprecia en las huellas resultantes, limpias, con signos de relieves altos y claros, de ejecución ortodoxa desde el punto de vista (paleo)gráfico y, por tanto, bien legibles.

Los dos signos corresponden a una misma letra del alfabeto fenicio, repetida, pero estampillada invertida, "en espejo". Esto es: las letras fueron incisas de modo ordinario sobre la matriz (en modo inverso a lo necesario para un sellado legible) y, como resultado, aparecen invertidos sobre las ánforas. Este tipo de inversiones no es raro en el labrado de sellos, incluso en aquellos de aparente mayor importancia o de matriz más cuidada (cf. por ejemplo la impronta gadirita recientemente hallada en Mértola, Sáez et al., en prensa). Es probable que estos "errores" se debieran a la intervención de especialistas en escritura fenicia, pero no en el grabado de sellos o en la apertura de cuños. Clara parece en este caso, al menos, la existencia de una mano bien versada en el trazado correcto (aunque invertido) de las letras.

En el documento que nos ocupa el grafema repetido es claramente una lamed, como se aprecia (una vez invertida la imagen) en lo curvo de sus trazos menores, correspondientes a la parte baja de la letra. Este cierre inferior del grafema estaba pues formado por un trazo, en ángulo bastante abrupto con el astil principal, curvado fuertemente en un corto ápice final - un conjunto difícilmente compatible con la parte alta de una nun, vid. infra). Debemos pues leer el texto de la matriz como ll.

Sellos con la repetición del grafema lamed se atestiguan en buen número sobre ánforas púnicas (véanse los ya recogidos por Ramon, 1995: 661667; hay hallazgos posteriores, incluso recientes, como por ejemplo Ferrer i Jané et al., 2014-1016: fig. 16:10). Se dan sobre matrices sobre todo cuadradas y rectangulares, en algún caso ovoides. Aunque la lectura lamed-lamed es clara en muchas de estas improntas, alguna de ellas presenta una cierta ambigüedad de lectura, pudiendo corresponder a una doble nun; como decíamos, no es el caso de las improntas que nos ocupan, claramente ejecutadas con una matriz de doble lamed. 
Este tipo de estampillas con la repetición de un mismo grafema constituyen claramente un grupo diferenciado dentro del estampillado púnico, realizado durante un tiempo preciso en talleres específicos del entorno metropolitano cartaginés (como confirma el soporte de los nuevos hallazgos, de tipología -y por lo tanto de datación y procedencia- coherente con el resto del conjunto). En concreto, como propusimos en trabajos anteriores (Zamora y Sáez, en prensa), parece probable que estas series de sellos bilíteros fuesen producto de talleres situados en el área de Le Belvedere, y que se utilizasen exclusiva o al menos preferentemente sobre envases de los tipos T-4215 y T-5231 en la transición del siglo IV al III a.C. y a lo largo de buena parte de éste. La aparición en estas series de todo el elenco de grafemas del alfabeto fenicio da a entender que no se trata de abreviaturas de nombres personales (como es el caso de otras estampillas púnicas con uno, dos o incluso más grafemas) sino de algún tipo de seriación, a modo quizá de numeración o marcado distintivo de grupos de producción sucesivos (como ya se ha sugerido al hilo de otros hallazgos similares registrados en Pompeya; Sáez y Zamora, 2019). En cualquier caso, se trata de una discusión que sobrepasa ampliamente el marco del estudio del estampillado anfórico cartaginés - y que conecta con una problemática multicultural, a escala mediterránea, que engloba la aparición y uso sistemático en algunos otros grandes focos productores de ánforas (como Marsella o diversas áreas del Egeo) de series de sellos epigráficos, en algunos casos bilíteros, que se han relacionado con la existencia de sistemas de contabilidad y gestión de la producción y de los talleres (Garlan, 2019; Py, 2001, entre otros). Es por tanto una cuestión que excede el espacio de presentación de estos materiales de Los Chinchorros, y que ha sido objeto de atención específica en otros trabajos (Zamora y Sáez, en prensa).

\subsection{Grafito postcocción en la base de cuenco "de tipo Kuass" (fosa de los cuadros C1/D1, Ni- vel 2) [Figura 7.1]}

En la base de un cuenco de cerámica "tipo Kuass", en el fondo exterior (algo apartado de su centro geométrico, pero siempre en esta zona del recipiente oculta durante su uso y no implicada en su función) se localiza un grafito, una marca completa en forma de cruz o aspa, incisa tras la cocción de la pieza (y realizada por tanto en cualquier momento de la vida del recipiente entre sus últimos momentos de presencia en el alfar y su amortización definitiva, incluyendo su recorrido comercial y su tiempo de uso). Este tipo de marcas, dada su simplicidad, son extraordinariamente comunes en cualquier época o lugar, estando presentes sobre formas de estas mismas producciones "de tipo Kuass" -también del área gaditana, Zamora, 2010: 346-347, fig. 3-y, en general, sobre muy variadas piezas de vajilla -igualmente en el territorio que nos ocupa, en puntos como Campo del Gayro, Centro Atlántida (Sáez, 2008: 408 y 429), calle Asteroides (Sáez, 2014b: 1668, fig. 3.182) o Torre Alta (Sáez, 2014b: 1727, fig. 3.241). Trazado, paralelos y cronología impiden su identificación como letra, como veremos en el apartado siguiente (en el que, dadas las similitudes entre este documento y el sucesivo, discutiremos también la interpretación de ambos).

\subsection{Grafito postcocción en la base de pátera de barniz negro (cuadro D5) [Figura 8.1]}

Otra marca en forma de aspa fue incisa en la base de una pieza de barniz negro itálico, una L1 de procedencia calena. Se trata de nuevo de un grafito inciso sobre la arcilla seca con decisión, dando lugar a trazos no muy gruesos pero de cierta profundidad. En este caso se conserva en modo fragmentario a causa de la rotura principal de la pieza pero, a pesar de ello, se advierte formado por dos trazos entrecruzados (no pareciendo probable, al hilo de lo conservado y de otros numerosos paralelos, que existieran originalmente más líneas en el área perdida). Ambos trazos son rectos, sin ningún tipo de curvatura que induzca a pensar en un trazado escritural. Como en el caso anterior, no se trata de una letra fenicia, tanto porque no se aprecia en la mano que lo trazó costumbre o gesto de escribir alguno como porque, en la cronología de la pieza y su contexto, no existe ningún grafema fenicio formado por el mero entrecruzarse de dos líneas.

Es pues una marca no grafemática, una de las más básicas posibles, en forma de cruz o aspa. Marcas como esta aparecen en recipientes cerámicos fenicios (y no sólo) de casi toda época y lugar (véase lo dicho en el apartado anterior). Abundan en los fondos, siendo una parte de ellas (pero en modo alguno todas) fruto de un grabado en fresco, sobre la arcilla del recipiente antes de su secado 
y horneado. Ello implica que al menos una parte de estos signos se realizaron en el alfar, durante el proceso productivo, como quizá era también el caso de al menos algunas de las marcas grabadas en seco, como las que nos ocupan. Pudieron pues estar al servicio de la organización interna del trabajo del taller (diferenciando ejemplares según su calidad, posición en el proceso de factura o incluso su destino final, por ejemplo) sin negarles tampoco la función de "firma" de alfarero que muchas veces también se les atribuye (si bien su simplicidad, máxima en el caso que nos ocupa, no parece del todo práctica a tal propósito). Su posición en los fondos, que impedía que las marcas interfirieran en la funcionalidad o estética del producto final, estaría también en consonancia con esta función de marcado productivo en el alfar.

No es sin embargo imposible, en casos como los que nos ocupan de marcados en seco, que el signo fuera añadido en un momento posterior, como parte del recorrido comercial de la pieza (pues las marcas mercantiles, comunes en la identificación de individuos o lotes, tienden también a situarse en los fondos de los recipientes, bien visibles en apilamientos inversos pero ocultos y no perjudiciales al propósito de la pieza durante su uso) e incluso como parte de su vida útil (a modo de "marca de propiedad" o, simplemente, diferenciación práctica). No obstante, la simplicidad del signo en aspa parece más en consonancia con un rápido y simple procedimiento artesano, más que comercial o de uso.

\subsection{Grafito postcocción sobre bol de barniz ne- gro itálico (cuadro D5) [Figura 8.2]}

Sobre un bol de paredes rectas (una forma L27 de barniz negro itálico, quizá una producción calena) se localiza otra marca incisa postcocción, en este caso en la cara externa de la pieza. Se trata de un fragmento de pequeño tamaño, que interrumpe dos trazos en ángulo (que forman un vértice poco preciso). Rectas y poco cuidadas, estas líneas visibles pudieron ser tal cual un signo simple o parte de un signo más complejo, incompleto; pero con seguridad no formaban un grafema. Aunque su posición, en una pared externa y por tanto no oculta a la vista, suele corresponder a marcados de propiedad o de diferenciación de uso, lo pequeño y fragmentario del documento aconseja no aventurarse demasiado en este tipo de interpretaciones.

\subsection{Estampilla circular sobre ánfora gaditana (cuadro C14, pozo PZ-5) [Figura 10]}

Este contexto, como se ha descrito en apartados anteriores, proporcionó un conjunto de ánforas locales e importadas entre las cuales se encontraba una T-12112 con una estampilla circular en la zona baja del cono superior, con una iconografía compuesta por un delfín junto a dos símbolos cuya morfología y trazado son más difíciles de leer. El motivo circular no es un círculo macizo (esto es: no se trata de un disco interpretable como una iconografía solar o de otro tipo) sino una incisión en forma de anillo irregular. Ocupa un lugar central en el área liberada en la matriz por la figuración y parece estar acompañado por unos trazos rectos a unos de sus lados, escasamente visibles, que podrían corresponder a una letra (convirtiendo en consecuencia al propio círculo en otra). De este modo, al menos dos grafemas se extenderían por un área de otra manera extrañamente libre de la matriz.

El círculo correspondería con toda seguridad a una letra fenicia ayin, mientras que los trazos contiguos no tendrían una lectura clara. Con ciertas iluminaciones parecerían compatibles con un grafema lamed - que podría también ser una nun, dada la imposibilidad de discernir detalles en esa zona de la impronta. La orientación de la lectura también resulta ambigua, pues, incluso aceptando una lectura lamed, la combinación ayin-lamed podría también leerse como una secuencia lamed-ayin. Otras estampillas epigráficas púnicas que presentan estas mismas dos letras (vid. Ramon, 1995: fig. 219, nos. 692-693) parecen más bien recoger una lectura ayin-lamed, que es además, como en seguida veremos, más sencilla de interpretar.

En uno u otro caso, se trataría muy probablemente de una estampilla con la presencia de la abreviatura de un nombre personal (en este caso acompañada de un motivo figurativo) en paralelo a la gran abundancia de estampillas púnicas interpretables de este modo (que a su vez siguen un sistema de abreviatura de nombres propios también presente en algunas estelas púnicas, Chabot, 1945). Si se tratara de la secuencia ayin-lamed, esta podría abreviar alguno de los varios nombres personales fenicio-púnicos de elemento inicial ' $a b d$ - que presentan una lamed en el segundo elemento antroponímico, como por ejemplo, con lamed en posición final, ' $b d b$ l. Con nun final, podría tratarse de nombres como 'bdskn, 'bdșpn o el muy 
común 'bd’šmn. Con otro tipo de formación, la secuencia podría corresponder a antropónimos también muy atestiguados como 'zrb'l (véase Benz, 1972: 150-153, 153-154, 162, 163, 167-170).

No es pues difícil postular una abreviatura antroponímica para la más probable lectura ayin-lamed, mientras que resultaría más complejo si la lectura fuera la inversa - aunque existen nombres de componente inicial $n^{c} m$ que podrían de algún modo corresponder a una abreviatura nun-ayin (Benz, 1972: 147) y podría incluso interpretarse la secuencia lamed-ayin por la presencia de una preposición inicial (de manera parecida a como puede hacerse con la estampilla con $l / n$ inicial añadida -con por cierto la figuración de un crustáceo en posición similar al delfín en la que nos ocupa- aparecida en Los Cañares; Zamora, 2010: 336-342). Son, en cualquier caso, opciones más forzadas y quizá por ello menos probables.

Sea como fuere, estaríamos ante un tipo de estampillado diverso del caso de las marcas selladas sobre las ánforas cartaginesas documentadas en el vertedero de los cuadros C1/D1. En este caso, el sellado dejaba sobre el ánfora el nombre de un individuo, ya fuera un propietario, artesano o un responsable de taller en funciones de control técnico o práctico, ya fuera un inspector o magistrado encargado del control o sanción de la producción alfarera (manifestado sobre una parte mínima del conjunto).

\section{Conclusiones}

El conjunto de objetos estudiado en estas páginas constituye una mínima parte del total de ítems documentado en las excavaciones llevadas a cabo en el solar situado junto a la calle San Bartolomé de "extramuros" de Cádiz, en el área de Los Chinchorros. Se trata además de documentos aparentemente modestos. Sin embargo, como se ha ido desgranando en los apartados anteriores, aportan interesantes datos no sólo para el mejor conocimiento de la historia local, sino también para la mejor comprensión de fenómenos históricos de escala mediterránea.

En este sentido, especialmente interesantes resultan los nuevos hallazgos para ampliar cuanto sabemos de las prácticas de estampillado anfórico, tanto locales como de ámbito cartaginés, propias de los siglos IV a II a.C. Estos sellos, su iconografía y contenido epigráfico, su estructura y posición, así como las informaciones aportadas por su examen microscópico, permiten añadir nuevos datos sobre su estampado en el marco de la cadena operativa de los alfares, sobre sus matrices y el trasfondo funcional de estas y, en definitiva, con la función o funciones del entero sistema en los diferentes ámbitos culturales y económicos del Mediterráneo helenístico en los que este se atestigua.

Más aparentemente humildes son los grafitos en función de marca también estudiados en este trabajo, simples y, en dos casos, coincidentes con un formato bien conocido y muy repetitivo de marcado: el trazado de un aspa en la cara externa de la base de formas cerámicas de mesa. Son de todos modos testimonios a no desdeñar, de cara a futuros estudios sistemáticos de este tipo de marcados y permiten en cualquier caso constatar su vigencia también durante los siglos III-II a.C., sobre vajilla local e importada utilizada entre los trabajadores del centro conservero ubicado en este punto del territorio insular de Gadir/Gades (siguiendo una práctica que sabemos era también habitual en las alfarerías coetáneas situadas en la actual San Fernando).

El estudio de los sellos recuperados en el solar es por tanto una aportación significativa no sólo para el análisis de la propia secuencia del sitio y, en particular, del saladero, sino también, siempre bajo perspectiva local, para ampliar el catálogo de marcas, aportar datos sobre sus contenidos (figurativos y/o epigráficos, según el caso) y sobre el proceso de estampillado, hasta ahora uno de los aspectos peor conocidos de la potente actividad alfarera de Gadir/Gades. En este sentido, y ya con un alcance que podría transcender la esfera local, muy sugerente resulta que las marcas sobre ánforas T-8211 de fábrica gadirita (las dos del Nivel 2 y aquella del Nivel 1 de la fosa-vertedero excavada entre los cuadros C1/D1) fueran en todos los casos estampilladas en un momento muy inicial del proceso de fabricación de los envases, con la arcilla muy húmeda (como denotan la falta de relieve y las superficies irregulares, rugosas, derivadas de que parte de la pared quedase adherida a la matriz) e incluso antes de que se trazase la incisión que sistemáticamente se realizaba para indicar la altura superior de las asas (como se ha visto para los sellos con representación de un casco griego y de un ave) y que por tanto implica el estampillado del cuerpo del ánfora antes del añadido de las propias asas. Todos estos indicios sugieren que las personas encargadas de marcar los envases debían por tanto tener una presencia relativamente 
constante en los talleres, participando de las fases de torneado y ensamblado de las diversas partes de las ánforas, previas al secado al aire de los envases terminados; y que la función de los sellos y el propósito del sellado de los contenedores (tanto si se trataba del resultado de una inspección/ sanción o de un procedimiento práctico interno al alfar, relativo a la producción o a la ulterior comercialización de las ánforas, por ejemplo) no requería de la finalización completa de los recipientes. Resulta imposible determinar si estos individuos que sellaban las ánforas serían funcionarios locales, clientes, o, como parece más probable, oligarcas o propietarios impulsores del negocio e incluso artesanos; pero los hallazgos que presentamos acotan e iluminan de forma interesante, segura y novedosa, su manera de funcionar.

También los emblemas presentes en los sellos y su epigrafía proporcionan informaciones de interés sobre el marcado y sus autores, en este caso confirmando lo que ya se advertía en testimonios anteriores: los elementos figurativos conocidos hasta el momento aluden a símbolos que no parecen poder identificarse con distintivos ciudadanos, sino personales; y, del mismo modo, las inscripciones relacionadas con ellos corresponden a nombres personales, aludiendo a individuos y no a la ciudad o a colectivos concretos. Por ello cabe suponer que, más que ante un sistema oficial de control (cuantitativo o cualitativo), nos encontraríamos ante procedimientos de marcado más bien debidos a la iniciativa privada y puntual de agentes involucrados en la producción, quizá a alto nivel.

Finalmente, debemos destacar que la presencia de varias estampillas sobre envases cartagineses acilindrados (T-4215 y T-5231) permite no sólo constatar el consumo de productos alimentarios manufacturados probablemente en la propia metrópolis centromediterránea o su entorno inmediato a lo largo del tramo final del siglo IV o la primera mitad del III a.C., sino que también ilustra con nitidez la coexistencia de distintas tradiciones (y probablemente funciones) dentro del marco del estampillado anfórico púnico (como ya se sugirió a propósito de otros sellos bilíteros cartagineses en Sáez y Zamora, 2019). Sin volver a insistir en las características particulares de los motivos y contenidos epigráficos de cada una de estas modalidades (gaditana y cartaginesa), cuestiones ya tratadas en los apartados precedentes, sí consideramos de interés recalcar la probable existencia de significativas diferencias tanto en las matrices empleadas como en su función o significado.

Respecto a la primera de estas cuestiones, si para el caso gaditano todas las marcas estudiadas hasta el momento parecen responder a impresiones más o menos puntuales de anillos signatarios no específicamente diseñados para este fin, en el caso cartaginés el menor cuidado en la labra de los motivos, la mayor diversidad en cuanto a dimensiones y formas de las cartelas, así como la preponderancia de los sellos con contenido exclusivamente epigráfico, permiten sospechar una mayor variabilidad dentro de esta práctica y el que, al menos en una parte de los talleres, pudieran haberse desarrollado con anterioridad al siglo II a.C. punzones específicos para el estampillado anfórico (como sabemos que se hacía con los punzones empleados para las estampillas de rosetas, ovas o palmetas usadas sobre la vajilla de mesa). En cierto modo esto podría explicar la mayor abundancia de sellos cartagineses (que permiten incluso, como sucede en el yacimiento que nos ocupa, que aparezcan en un mismo contexto ánforas selladas por una misma matriz, pertenecientes quizá a un mismo lote productivo y a un mismo grupo exportado) y por qué en el caso gaditano, a pesar de contar con una producción en masa de contenedores de transporte, la tasa de envases estampillados es muy baja para esta etapa. Como se ha planteado en trabajos precedentes (Sáez et al., en prensa), probablemente esta práctica no se haría más homogénea desde el punto de vista técnico hasta avanzado el siglo II a.C., quizá ya con ambas áreas, gaditana y cartaginesa, bajo dominio romano, puesto que no parece que el uso de anillos personales y/o gemas como instrumentos de sellado de ánforas desapareciese hasta el tramo final de dicha centuria.

La segunda cuestión tiene aún si cabe más proyección, aunque los argumentos arqueológicos disponibles para la discusión son menos sólidos. Los sellos cartagineses aparecidos en Los Chinchorros pertenecen a un grupo minoritario y hasta ahora poco estudiado que se caracteriza por la repetición de un mismo grafema, una combinación que con seguridad no corresponde a abreviaturas de nombres propios sino que, más bien, parece relacionarse con un sistema elaborado de control o gestión administrativa de la producción de determinados talleres (similar al propuesto para el caso de la producción de ánforas de Massalia; véase Py, 2001). Las marcas de factura gaditana sin embargo son mucho más escasas y fundamentalmente anepígrafas. En los pocos casos que has- 
ta ahora han revelado la presencia de grafemas junto a los motivos principales parece que dichas inscripciones pueden relacionarse con facilidad con antropónimos o abreviaturas de antropónimos. Los sellos de Los Chinchorros han aportado ejemplos de ambos modelos de sellado, que ni siquiera son coincidentes en la zona de colocación de las estampillas: mientras que las cartaginesas se colocaron preferentemente sobre las asas, en el borde o en el cuello, en áreas de alta visibilidad y fácil acceso, las gadiritas fueron colocadas en la mayoría de casos conocidos sobre el cuerpo (bien en la parte alta o hacia el centro de los envases, en una posición mucho menos visible). Las notorias diferencias entre ambas tradiciones en múltiples aspectos (frecuencia, posición, contenidos, cuños, etc.) sugieren que su función pudo ser igualmente distinta; y mientras que el sellado bilítero empleado por alguno o algunos talleres cartagineses pudo estar concebido con un propósito sistemático vinculado a la gestión, las marcas gadiritas parecen más ocasionales y no específicas, quizá destinadas puntualmente a diferenciar partidas concretas o sancionar la actividad de alfareros o cuadrillas específicas (una funcionalidad que, en cualquier caso, el estampillado anfórico debió tener también en los talleres centromediterráneos, donde el uso de sellos bilíteros de grafema repetido indicando posibles seriaciones $-y$ de algunos monolíteros con posible función análoga- estuvo, como decíamos, circunscrita a talleres concretos en momentos específicos).

A pesar de la modestia cuantitativa de los documentos estudiados, es evidente que las preguntas que motivan su estudio son de gran alcance, por lo que no se pretende con estas reflexiones dejar cerradas estas cuestiones sino por el contrario plantear un escenario de debate que deberá enriquecerse con nuevos hallazgos y propuestas. Será por tanto necesario continuar ampliando el análisis de contextos similares a Los Chinchorros en el área suburbana insular y, en general, en el marco de la bahía, con el doble objetivo de arrojar por un lado nueva luz sobre la complejidad de la evolución de los usos del suelo en el territorio de $\mathrm{Ga}$ dir/Gades durante la etapa helenística y, por otro, de recabar nueva información relativa a marcas, sellos y grafitos - información que, como hemos visto, a la vez ilumina y trasciende los problemas locales, parte de un escenario Mediterráneo mucho más amplio.

\section{Agradecimientos}

Este trabajo es resultado de los proyectos de investigación ERGASTERIA. Arqueología experimental $y$ virtual para el estudio de los procesos de producción anfórica y comercialización en la Protohistoria (Proyectos I+D+i FEDER Andalucía 2014-2020, Consejería de Economía y Conocimiento de la Junta de Andalucía; Ref. US-1266376) y GREPURE. Grecia Púnica Redescubierta (impulsado y financiado por la Fundación BBVA y la Sociedad Española de Estudios Clásicos, Programa Logos 2019, Ref. US2020/1029), así como el proyecto Estudio y edición de inscripciones fenicias y púnicas de la Península Ibérica y sus aledaños inéditas o mal conocidas - Parte II (FFI2013-46126-P) del Plan Estatal de Investigación Científica y Técnica y de Innovación (MINECO).

\section{Bibliografía}

ALFARO ASINS, Carmen. 1988: Las monedas de Gadir/Gades. Fundación para el Fomento de los Estudios Numismáticos. Madrid.

ARÉVALO GONZÁLEZ, Alicia. 2006: "Sobre el posible significado y uso de algunas contramarcas en moneda de Gadir/Gades". Nvmisma, año LVI, n. ${ }^{\circ} 250$ (enero-diciembre), pp. 69-100.

ARÉVALO GONZÁLEZ, Alicia. 2010: "De la manipulación a la falsificación de moneda en Gadir". En M. CAMPO (coord.): Falsificació i manipulació de la moneda. XIV Curs d'història monetària d'Hispània, pp. 41-53. Museu Nacional d'Art de Catalunya. Barcelona.

ARÉVALO GONZÁLEZ, Alicia; MORENO PULIDO, Elena. 2016: "La moneda en la necrópolis de Gadir/Gades". En A. ARÉVALO (coord.): Monedas para el más allá: uso y significado de la moneda en las necrópolis tardopúnicas y romanas de Ebusus, Gades y Malaca, pp. 75-194. Servicio de Publicaciones de la Universidad de Cádiz. Cádiz.

BELIZÓN ARAGÓN, Ricardo; SÁEZ ROMERO, Antonio Manuel; DE LA BANDERA, María Luisa. 2020: "Un nuevo conjunto de enterramientos de la necrópolis púnica de Gadir. Excavaciones en el solar de la Avenida de Andalucía 1-3 en Cádiz". En S. CELESTINO y E. RODRÍGUEZ (eds.): Un viaje entre el Oriente y el Occidente del Mediterráneo / A Journey between East and West in the Mediterranean. Mytra 5, vol. III, pp. 1013-1037. IAM-CSIC. Mérida. 
BENZ, Frank L. 1972: Personal names in the Phoenician and Punic inscriptions (Studia Pohl 8). Pontificio Istituto Biblico. Rome.

BERGES, Dietrich. 1998: "Los sellos de arcilla del archivo del templo cartaginés". Cuadernos de Arqueología Mediterránea, 4, pp. 111-132.

BLANCO JIMÉNEZ, Francisco. 1991: “Excavaciones de urgencia en un solar de la calle Gregorio Marañón. Cádiz". Anuario Arqueológico de Andalucía. Tomo III, pp. 78-81.

BRIQUEL-CHATONNET, Françoise. 2007: "Première ancre à inscription néopunique". Orientalia, 76(1), pp. 24-29.

CHABOT, Jean-Baptiste. 1945: "Essai sur le système d'abreviation usité dans l'écriture phénicienne". Bulletin Archéologique su Comité des Travaux Historiques et Scientifiques, 1943-45, pp. 217-224 y 237-244.

DE LA BANDERA ROMERO, María Luisa; ORTEGA FELIÚ, Inés; GÓMEZ TUBÍO, Blanca; ONTALBA SALAMANCA, María Ángeles; RESPALDIZA GALISTEO, Miguel Ángel. 2010: "Caracterización del taller de orfebrería de Gadir mediante técnicas de análisis nucleares". Mainake, XXXII(1), pp. 37-59.

FERNÁNDEZ GÓMEZ, Jordi H.; PADRÓ PARCERISA, Josep, 1986: Amuletos de tipo egipcio del Museo Arqueológico de Ibiza. Treballs del Museu Arqueològic d'Eivissa i Formentera. Ibiza.

FERRER ALBELDA, Eduardo. 1995: Los púnicos en Iberia. Análisis historiográfico y arqueológico de la presencia púnica en el sur de la Península Ibérica. Tesis Doctoral. Universidad de Sevilla. Sevilla.

FERRER I JANÉ, Joan; ASENSIO I VILARÓ, David; PONS I BRUN, Enriqueta. 2014-2016: "Novetats epigràfiques ibèriques dels segles V-IV ac del Mas Castellar (Pontós, Alt Empordà)". Cypsela, 20, pp. 117-139.

GAMER-WALLERT, Ingrid, 1978: Äegyptische und ägyptisierende Funde von der Iberischen Halbinsel. Tübinger Atlas des Vorderen Oriens, Reihe B 21. Reichert, Wiesbaden.

GARCÍA FERNÁNDEZ, Francisco José; FERRER ALBELDA, Eduardo; SÁEZ ROMERO, Antonio Manuel. 2016: "The hellenisation of taste in Turdetania: tradition and change in ceramic assemblages in the valley of the Guadalquivir in the Late Iron Age". En S. JAPP y P. KÖGLER (eds.): Traditions and Innovations: Tracking the Development of Pottery from the Late Classical to the Early Imperial Period. Proceedings of the 1st Conference of IARPotHP, pp. 29-41. IARPotHP. Viena.

GARCÍA GONZÁLEZ, David; LÓPEZ CHAMIZO, Sonia; GARCÍA ALFONSO, Eduardo. 2018: La Tumba del Guerrero: un enterramiento excepcional en la Málaga fenicia del siglo VI a.C. Consejería de Cultura de la Junta de Andalucía. Sevilla.

GARLAN, Yvon. 2019: "La finalité du timbrage amphorique grec: une ténébreuse affaire". En $\mathrm{N}$. BADOUD y A. MARANGOU (dirs.): Analyse et exploitation des timbres amphoriques grecs, pp. 15-20. Presses Universitaires de Rennes. Rennes.

HALDANE, Douglas. 1986: "Wooden Anchor Arm Construction". International Journal of Nautical Archaeology, 15, pp. 163-166.

HIGUERAS-MILENA CASTELLANO, Aurora; SÁEZ ROMERO, Antonio Manuel. En prensa: "La circulación de productos envasados en ánforas en la Gades republicana: nuevos datos procedentes de contextos subacuáticos de La Caleta (Cádiz)". En H. UROZ y A. RIBERA (eds.): Congreso Internacional «Cultura material romana en la Hispania Republicana. Contextos privilegiados y estado de la cuestión» (Lezuza, Albacete, 22-24 de abril de 2016).

HIXENBAUGH, Randall. 2019: Ancient Greek Helmets: A Complete Guide and Catalog. Hixenbaugh Ancient Art Ltd. Nueva York.

KAPITÄN, Gerhard. 1984: "Ancient anchors - Technology and classification". International Journal of Nautical Archaeology, 13(1), pp. 33-44.

LAVADO FLORIDO, María Luisa. 2008: Memoria preliminar de la excavación arqueológica en un solar en UE-EX-19 y 20. Los Chinchorros de Cádiz. Unpublished. Informe inédito depositado en la Delegación provincial del Cultura de Cádiz, Cádiz.

LAVADO FLORIDO, María Luisa. 2010: "Ajuar funerario de Los Chinchorros. Cádiz". En M.D. LÓPEZ y E. GARCÍA (eds.): Cádiz y Huelva. Puertos fenicios del Atlántico. Catálogo de la Exposición (Museo de Cádiz-Museo de Huelva, 2010-2011), pp. 314-315. Fundación Cajasol y Junta de Andalucía. Cádiz, Huelva.

LÓPEZ AMADOR, Juan José; RUIZ GIL, José Antonio. 2010: "Las ofrendas del santuario púnico-gaditano de La Algaida (Sanlúcar de Barrameda)". En E. MATA y F. GILES (eds.): Cuaternario y Arqueología. Homenaje a Francisco Giles Pacheco, pp. 271-279. Diputación Provincial de 
Cádiz y Servicio de Publicaciones: Asociación Profesional del Patrimonio Histórico-Arqueológico de Cádiz.

LUACES, Max; SÁEZ ROMERO, Antonio Manuel. 2019: "Late Punic amphorae in 'Roman' shipwrecks of southern Gaul: the evidence of a trading route from the Atlantic and the Strait of Gibraltar region to the Tyrrhenian Sea". En A. PEIGNARD-GIROS (ed.): Daily Life in a Cosmopolitan World: Pottery and Culture during the Hellenistic Period. Proceedings of the 2nd Conference of the International Association for Research on Pottery of the Hellenistic Period, pp. 143-157. Phoibos Verlag. Viena.

MANI HURTER, Silvia; LIEWALD, Hans-Joachim, 2006: "Die frühesten Typen der Elektronprägung von Kyzikos. Thunfische, Thunfischköpfe und -hinterhälften". Schweizerische Numismatische Rundschau, 85, pp. 5-26.

MARTÍN RUIZ, Juan Antonio; GARCÍA CARRETERO, Juan Ramón. 2018: "Greek Armament from the South of the Iberian Peninsula during the 1st Millennium BC". Athens Journal of History, 4(4), pp. 279-294.

NIVEAU DE VILLEDARY, Ana María, 2003: “El uso ritual de la vajilla cerámica en la necrópolis púnica de Cádiz". Archivo Español de Arqueología, 76(187-188), pp. 3-30. https://doi. org/10.3989/aespa.2003.v76.103.

NIVEAU DE VILLEDARY, Ana María, 2004: Las cerámicas gaditanas "tipo Kuass". Bases para el análisis de la Bahía de Cádiz en época púnica. Bibliotheca Archaeologica Hispana. Madrid.

NIVEAU DE VILLEDARY, Ana María, 2009: Ofrendas, banquetes y libaciones. El ritual funerario en la necrópolis púnica de Cádiz. Secretariado de Publicaciones de la Universidad de Sevilla y Servicio de Publicaciones de la Universidad de Cádiz. Sevilla.

NIVEAU DE VILLEDARY, Ana María; RUIZ MATA, Diego. 2000: "El poblado de Las Cumbres (Castillo de Doña Blanca): Urbanismo y materiales del s. III a.C.". En M. BARTHÉLEMY y M.E. AUBET SEMMLER (coords.): Actas del IV Congreso Internacional de Estudios Fenicios y Púnicos, vol. II. Cádiz, pp. 893-904. Servicio de Publicaciones de la Universidad de Cádiz.

NIVEAU DE VILLEDARY, Ana María; ZAMORA LÓPEZ, José Ángel, 2009: “La necrópolis como centro de consumo: a propósito de dos nuevos sellos anfóricos con inscripciones púnicas procedentes de Cádiz". Madrider Mitteilungen,
51, pp. 151-182.

PADRÓ I PARCERISA, Josep, 1985: Egyptian-Type Documents from the Mediterranean Littoral of the Iberian Peninsula before the Roman Conquest. Vol III. Study of the Material. Andalusia. BRILL Deutschland GmbH. Brill, Leiden.

PERDIGONES MORENO, Lorenzo; MUÑOZ VICENTE, Ángel; PISANO, Giovanna, 1990: La necrópolis fenicio-púnica de Cádiz. II Università degli studi di Roma, Dipartimento di storia. Roma.

PY, Michel. 2001: "Chronologie des timbres imprimés sur les amphores massaliètes". Lattara, 14, pp. 209-231.

RAMON TORRES, Joan. 1995: Las ánforas fenicio-púnicas del Mediterráneo Central y Occidental. Universitat de Barcelona, Colección Instrumenta, 2. Barcelona.

RAMON TORRES, Joan; ZAMORA LÓPEZ, José Ángel. 2018: "Una nueva estampilla sobre ánfora púnico-ebusitana hallada en ses Païsses d'Artà (Mallorca): Nueva luz sobre una distintiva forma ebusitana de estampillado". Archivo Español De Arqueología, 91, pp. 205-216.

REDISSI, Taoufik. 1991: "Étude de quelques amulettes puniques de type egyptisant". Revue des Études Phéniciennes-Puniques et des Antiquités Libyques, 6, pp. 95-139.

SÁEZ ROMERO, Antonio Manuel. 2008: La producción cerámica en Gadir en época tardopúnica (siglos -III/-I). BAR International Series, 1812. Oxford.

SÁEZ ROMERO, Antonio Manuel. 2014a: "Fish Processing and Salted-Fish Trade in the Punic West: New Archaeological Data and Historical Evolution". En E. BOTTE y V. LEITCH (eds.): Fish \& Ships: Production et commerce des salsamenta durant l'Antiquite (Actes de l'atelier doctoral, Rome 18-22 juin 2012), pp. 159-174. Bibliothèque d'Archéologie Méditerranéenne et Africaine, vol. 17, Publications du Centre Camille Jullian. Aix-en-Provence.

SÁEZ ROMERO, Antonio Manuel. 2014b: Alfares y saladeros de Gadir. Una aproximación arqueológica a la economía conservera de la Bahía de Cádiz en época púnica y tardopúnica (siglos VI $a-$-I). Tesis Doctoral. Universidad de Cádiz. Cádiz.

SÁEZ ROMERO, Antonio Manuel. 2018: “¿Tipologías mediterráneas vs. tipologías locales? Valoraciones metodológicas a partir de una nueva propuesta de sistematización de la producción anfórica gaditana". Ex Officina Hispa- 
na: cuadernos de la SECAH, 3, pp. 39-80.

SÁEZ ROMERO, Antonio Manuel; BELIZÓN, Ricardo. 2020: “¿Qué se cuece? Evolución formal, estándares de capacidad y análisis funcional de las cerámicas «de cocina» fenicio-púnicas de Gadir". En C. GÓMEZ, G. PÉREZ y A. VENDRELL (coords.): La alimentación en el mundo fenicio-púnico. Producciones, procesos y consumos, pp. 197-240. Universidad de Sevilla.

SÁEZ ROMERO, Antonio Manuel; FERRER ALBELDA, Eduardo. 2018: "Dioses de barro. Sellos con simbología religiosa de la producción anfórica de Gadir (siglos IV-II a.C.)". En A. D. NAVARRO y E. FERRER (eds.): Trabajo Sagrado. Producción y representación en el Mediterráneo occidental durante el I milenio a.C., pp. 272-307. Universidad de Sevilla. Sevilla.

SÁEZ ROMERO, Antonio Manuel; GARCÍA FERNÁNDEZ, Francisco José; ZAMORA LÓPEZ, José Ángel; PALMA, María Fátima. En prensa: "Una nueva estampilla púnica procedente de las excavaciones de la Biblioteca Municipal de Mértola (Portugal): Interrogantes y perspectivas en el estudio del sellado anfórico occidental". Madrider Mitteilungen, 61.

SÁEZ ROMERO, Antonio Manuel; GUTIÉRREZ, José María; REINOSO DEL RÍO, Cristina. 2020: “Un asentamiento de época púnica en la campiña costera de la Bahía de Cádiz. Estructuras, fases de uso y contextos materiales de Puerto-19". Archivo Español de Arqueología, 93, pp. 61-80.

SÁEZ ROMERO, Antonio Manuel; LAVADO FLORIDO, María Luisa. 2016: “Calle San Bartolomé / Los Chinchorros (Cádiz, España)". RAMPPA, Red de Excelencia Atlántico-Mediterránea del Patrimonio Pesquero de la Antigüedad. http:// ramppa.uca.es/cetaria/calle-san-bartolome-los-chinchorros. Acceso el 23 noviembre de 2020.

SÁEZ ROMERO, Antonio Manuel; LAVADO FLORIDO, María Luisa. 2019: “Cremaciones fenicias y un nuevo saladero de pescado púnico de Gadir. Avance de los hallazgos registrados en el área de Los Chinchorros (Calle San Bartolomé, Cádiz)". Habis, 50, pp. 49-81.

SÁEZ ROMERO, Antonio Manuel; LUACES, Max; MORENO PULIDO, Elena. 2016: "Late Punic or Early Roman? A 2nd century BC deposit from Gadir/Gades (Cadiz Bay, Spain)". HEROM - Journal on Hellenistic and Roman Material Culture, 5(1), pp. 27-78.
SÁEZ ROMERO, Antonio Manuel; THEODOROPOULOU, Tatiana; BELIZÓN ARAGÓN, Ricardo. 2020: "Atunes púnicos y vinos egeos en una taberna de la Grecia Clásica. Resultados iniciales del Corinth Punic Amphora Building Project". En S. CELESTINO y E. RODRÍGUEZ (eds.): Un viaje entre el Oriente y el Occidente del Mediterráneo / A Journey between East and West in the Mediterranean. Mytra 5, vol. II, pp. 817835. IAM y CSIC. Mérida.

SÁEZ ROMERO, Antonio Manuel; ZAMORA LÓPEZ, José Ángel, 2019: "Las importaciones anfóricas de tradición púnica procedentes del Mediterráneo Central". En D. BERNAL-CASASOLA y D. COTTICA (eds.): Scambi e commerci in area vesuviana. Roman and Late Antique Mediterranean Pottery, pp. 77-95. Archaeopress. Oxford. VERCOUTTER, Jean, 1945: Les objets égyptiens et égyptisants du Mobilier Funéraire Carthaginois. Bibliothèque Archéologique et Historique XL. París.

VOTRUBA, Gregory F;, ARTZY, Michal. 2016: "An Archaic Anchor Arm from Liman Tepe/Klazomenai, Turkey". International Journal of Nautical Archaeology, 45(2), pp. 450-456.

WROTH, Warwick, 1892: Catalogue of the Greek coins of Mysia. A Catalogue of the Greek coins in the British Museum. Londres.

ZAMORA LÓPEZ, José Ángel, 2010: “Poenica hispana I: documentos epigráficos fenicio-púnicos inéditos, mal conocidos o sujetos a nuevo examen procedentes de la Península Ibérica y su entorno". Mainake, 32, pp. 335-353.

ZAMORA LÓPEZ, José Ángel; NIVEAU DE VILLEDARY, Ana María, 2008: "Una nueva estampilla epigráfica sobre ánfora púnica hallada en la necrópolis de Cádiz". Habis, 39, pp. 57-78.

ZAMORA LÓPEZ, José Ángel; SÁEZ ROMERO, Antonio Manuel. En prensa: "Punic stamps with repeated graphemes. New insights on a specific series of seals impressed on Carthaginian amphorae (4th-2nd centuries BC)". Carthage Studies, 12. 